CRISIS COMMUNICATION, SPORTS AND TWITTER: HOW BAYLOR UNIVERSITY AND ITS FANS USED TWEETS TO COMMUNICATE DURING

THE 2015-2017 SEXUAL ASSAULT SCANDAL

A thesis
presented to
the Faculty of the Graduate School
at the University of Missouri-Columbia
In Partial Fulfillment
Of the Requirement for the Degree
Master of Arts
ERIN M. FRY
br. Cynthia Frisby, Thesis Supervisor

MAY 2017 
(C) Copyright by Erin M. Fry 2017

All Rights Reserved 
The undersigned, appointed by the dean of the Graduate School, have examined the thesis entitled

CRISIS COMMUNICATION, SPORTS AND TWITTER: HOW BAYLOR UNIVERSITY AND ITS FANS USED TWEETS TO COMMUNICATE DURING

THE 2015-2017 SEXUAL ASSAULT SCANDAL presented by Erin M. Fry, a candidate for the degree of master of arts, and hereby certify that, in their opinion, it is worthy of acceptance.

Professor Cynthia Frisby

Professor Brett Johnson

Professor Jim Flink

Professor Brian Houston 


\section{DEDICIATION}

To my family, especially my parents, Jan and Steve, and my sister, Kyra for their unwavering support, and to my dog, Max for the countless hours he spent supervising me as I worked to complete my thesis and degree. 


\section{ACKNOWLEDGEMENTS}

I have been so fortunate to have wonderful professors at the University of Missouri, and without the challenging coursework and the support I was given throughout my two years here, I would not have been able to complete this degree. I first want to thank my superb chair, Dr. Cynthia Frisby. I am so grateful for her advice and support throughout the research process. I would also like to thank my methodologist, Dr. Brett Johnson and Professor Jim Flink for their input and encouragement. I'm also appreciative of the time Dr. Brian Houston gave serving on my committee.

l'd also like to acknowledge and thank my professors at lowa State University who instilled in me a desire to learn and do more, and who also encouraged me to pursue my master's degree. I have been extremely lucky both during my undergraduate and graduate years to work with faculty that are caring, knowledgeable and who have pushed me to do more than I thought possible. This thesis is truly a testament to them. 


\section{TABLE OF CONTENTS}

Acknowledgements.............................................................................................................

Abstract ............................................................................................................... vii

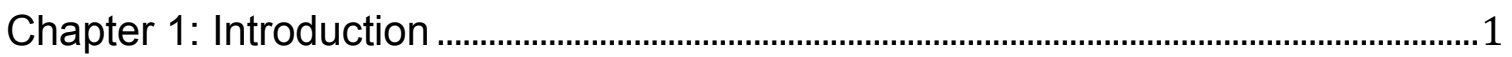

Statement of the problem ………………...................................................................

Purpose of the study

Chapter 2: Literature Review.....................................................................................

Sports Public Relations.................................................................................................

Sports Crises/Scandals _..................................................................................... 6

Crisis Communication ........................................................................................................

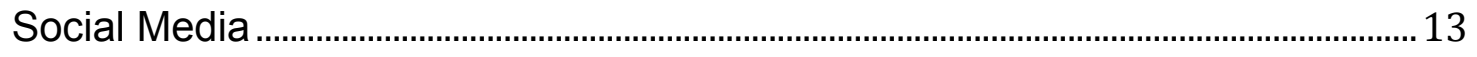

Social Media and Crisis Communication ………………................................................

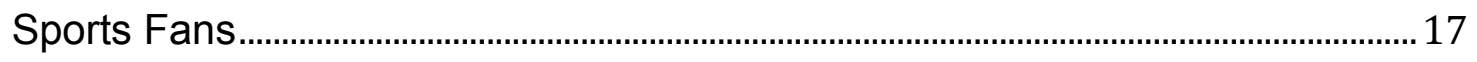

Sports Fans as Crisis Communicators on Social Media ............................................. 18

Chapter 3: Methodology ...................................................................................................22

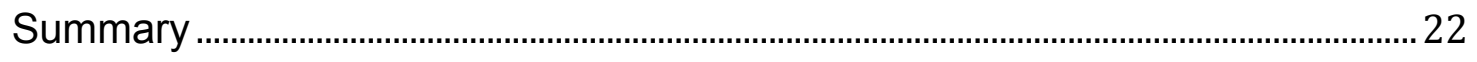

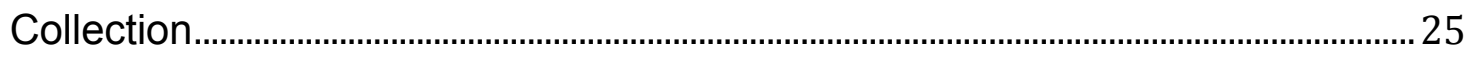

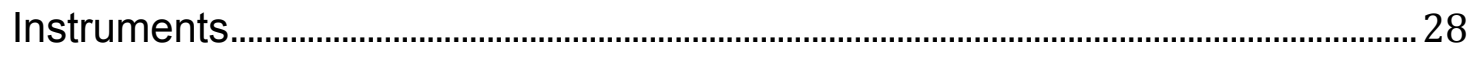

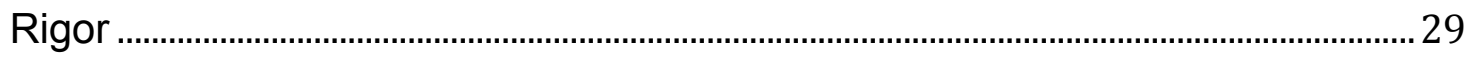

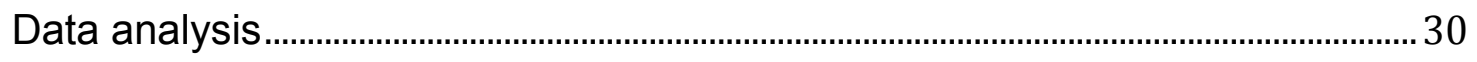

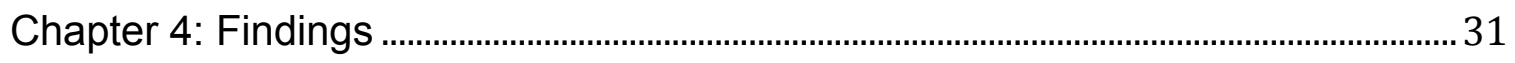

Baylor University ........................................................................................................ 32 


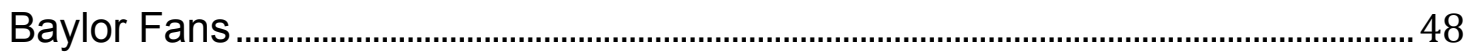

Chapter 5: Discussion and Conclusion …………………………………………………..... 73

Limitations and Future Research............................................................................

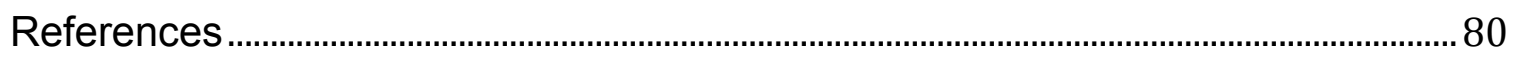

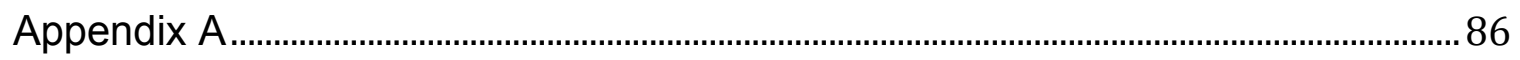

Appendix B

Appendix C

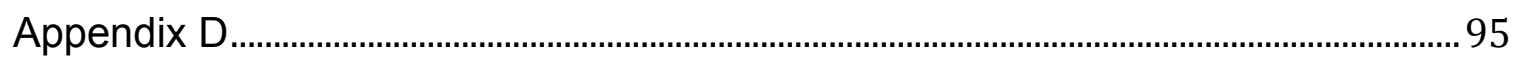

Appendix E 


\title{
CRISIS COMMUNICATION, SPORTS AND TWITTER: HOW BAYLOR UNIVERSITY AND ITS FANS USED TWEETS TO COMMUNICATE DURING THE 2015-2017 SEXUAL ASSAULT SCANDAL
}

Erin M. Fry

Cynthia Frisby, Thesis Supervisor

\begin{abstract}
Sports scandals are common, and "are almost as old as the sports themselves" (Lordan, 2014, p. 1). This thesis examined how Baylor University and its fans acted as crisis communicators on Twitter during the 2015-2017 football sexual assault scandal. Working from a grounded theory approach, the researcher conducted a constant comparative textual analysis of tweets sent out by fans and the university. Findings showed the three Baylor University accounts analyzed used the communication strategies of bolstering/reminder and corrective action most frequently but also used apology and diversion (Bruce and Tini, 2008). The analysis also revealed that while some fans supported the university, other fans turned against it. Fans used seven different crisis communication strategies during the scandal, including: scapegoat/shift the blame, diversion (Brown and Billings, 2013), attack the accuser, victimage, differentiation, bolstering/reminder and ingratiation. Unique to this study was how fans used diversion to draw attention to past scandals at Baylor.
\end{abstract}




\section{Chapter 1: Introduction}

Unfortunately, scandals are common among sports teams. Lordan (2014) notes that sports scandals "are almost as old as the sports themselves" (p. 1). Several scholars have studied sports scandals and how teams communicate during these crises; however, the amount of literature focusing on how fans can act as crisis communicators during a sports scandal is limited. It's important for practitioners to understand how fans can act as crisis communicators on behalf of a sports organization so that they can further foster this relationship in hopes of having additional communication tools (fans) to rely on during the scandal. This thesis looks to add to the literature available on fan-enacted crisis communication.

Sports scandals originate from a variety of wrongdoings, including sexual assault allegations. In recent years the conversation around college campus climate has focused on sexual violence. According to the National Sexual Violence Resource Center (2015), approximately 20 percent of women and 6 percent of men will be sexually assaulted while they're in college. The rate of sexual assaults on college campuses is alarming and receives extended media coverage, especially when athletes are accused of sexual assault. At Baylor University this is the scandal they're currently facing. In a scandal that has lasted a couple of years, several football players have been accused of sexually assaulting women, the athletic department and administration have been criticized for their handling of the assaults, many individuals have been fired, quit 
or excused from the program and the U.S. Department of Education has launched an investigation into the school's handling of Title IX complaints (Grosbard, 2016).

The media commonly expose sports scandals, and with social media the news has the potential to reach millions (Burroughs and Vogan, 2015). With the use of social media, the public can join and listen to the conversation. Individuals have the power to demand information immediately and can share this information with their friends and followers. Because sports fans have the opportunity to weigh in on the scandal, it is important that sports organizations and athletes are using social media effectively while communicating during a scandal.

\section{Statement of the problem}

Studying how sports fans act as crisis communicators is important to scholarship for a couple of reasons. First, theorists can help practitioners better understand how fans can act as a pseudo-internal members of a sports organization rather than an audience during a scandal. Understanding this unique shift in the relationship can help practitioners as they are building and strengthening the bond between the sports organization and its fans. In turn, when the sports organization undoubtedly faces a scandal, it will hopefully be able to rely on fans to act as crisis communicators on behalf of them. Second, this study hopes to build off of suggestions for future research posed in previous studies. This thesis looks to see if different crisis communication strategies are used compared to what has previously emerged in fan-enacted crisis 
communication studies. Additionally, this study hopes to expand upon existing literature that examines how fans can act as crisis communicators on behalf of a sports organization.

\section{Purpose of the study}

The purpose of this study is to understand and compare how Baylor University, the largest Baptist school in the world ("Mission statement," n.d.), and its fans acted as crisis communicators on Twitter during the 2015-2017 sexual assault scandal. Twitter was selected as the appropriate medium because it is widely used by sports media, teams, athletes and fans. This research is important for both practitioners and researchers. Researchers can use this information to guide future studies and help guide practitioners. Practitioners can use this research to understand how fans can enact crisis communication strategies either on behalf or against a sports organization during a scandal. Understanding this relationship can help practitioners determine how to further cultivate the relationship between the organization and fans so that they have additional communication tools (fans) to use during a scandal.

This thesis begins with a literature review that examines the scholarship on public relations in sports, sports scandals, crisis communication strategies, social media, social media and crisis communication, sports fans and sports fans as crisis communicators. Throughout the literature two research questions are posited about crisis communication strategies used on Twitter during the 20152017 Baylor University sexual assault scandal. Following the literature review is the methodology section. Here, the methodology—textual analysis—is explained 
and defended as the best method to help answer the research questions. The findings are presented next, followed by the discussion and conclusion. 


\section{Chapter 2: Literature Review}

\section{Sports Public Relations}

Dating back to the early 1900 s, most sports teams did not have a department that was solely responsible for communicating information to the media. In baseball, the first press office wasn't created until 1922 as a result of a big scandal—-the Black Sox scandal (Anderson, 2001). During the Black Sox scandal in 1919, in which eight players worked with gamblers to intentionally lose the World Series, baseball officials wanted to protect the reputation of America's favorite pastime, so they created the first press office, which was in charge of responding to media requests about the scandal (Anderson, 2001). Since then communication practitioners have become a staple in athletic organizations.

Today, public relations in sports is a necessary function because of the level of attention athletes and programs get from journalists, fans, community members, media outlets, scholars, sponsoring corporations and government entities (Ruihley, Pratt and Carpenter, 2016). Public relations can be defined as a "strategic form of communication which focuses upon the process of establishing a good relationship between an organization and the public, especially in terms of shaping its reputation and sending information" (Petrovici and Dobrescu, 2013, p. 121). Maintaining a good reputation between an athletic program and its constituents is important for brand image, team support and revenue. Additionally, if a good relationship is maintained, this relationship can be leveraged during a scandal, which frequently occurs in sports. 
According to Seeger, Sellnow and Ulmer (2003), the most important strategic activity in public relations for any organization is crisis planning. Planning ahead for crises allows an organization "to reduce uncertainty, decision time, response and recovery," which in turn will hopefully allow the organization to maintain some control over the situation (Pang, Cropp and Cameron, 2006).

\section{Sports Crises/Scandals}

In sports, a crisis is defined as a surprising or unpredictable incident that has the power to negatively affect the team's image, financial stability and credibility (Coombs, 2014; Jordan \& Smith, 2013; Seeger et al., 2003; Stoldt, Miller, Ayers \& Comfort, 2000). Sports crises are unique compared to crises experienced by organizations in other industries because most of the messages are shared via media coverage rather than a strategic advertising campaign. This is because sports organizations largely rely on the media to share their stories (Bruce and Tini, 2008). Additionally, if the scandal is occurring at a school in the NCAA, the university has further restrictions on how they communicate. Per NCAA legislation 19.01.3 Public Disclosure, schools and programs under investigation cannot disclose anything to the public until the final ruling has been made (NCAA, 2016). This makes a scandal involving college athletics even more unique.

A crisis can have a short or long life depending on the nature of the crisis and how the organization involved handles it. A crisis continues until the organization experiencing it returns to a "near normal operational state," which can be defined differently by the sports organization or fans (Jordan and Smith, 
2013). The Baylor football sexual assault scandal, which is the subject of this study, currently has a crisis life of nearly two years. For the purposes of this study, the beginning of Baylor's crisis is considered September 2, 2015, the date Pepper Hamilton was hired to conduct an internal investigation of how the university handled sexual violence reports. In accordance with Brown and Billings' (2013) study, I will operate under the understanding that a sports scandal qualifies as a type of crisis, which is why I use the terms interchangeably.

A sports crisis can be categorized as a physical, on-field, family, corporate or player personnel crisis (Favorito, 2012; Jordan and Smith, 2013). A physical crisis includes issues related to the escape plans, security, blackouts and anything else related to the physical space a sporting event takes place in. An on-field crisis occurs when a player or fan is injured. A family crisis includes anything that happens after hours or on the athletes' own time. A corporate scandal includes anything that happens within the organization such as financial failures and corruption, layoffs and compliance issues. Lastly, player personnel crises are caused due to trading or releasing players and coaches (Favorito, 2012; Jordan and Smith, 2013). This study is concerned with a crisis that can be classified as a family, corporate or player personnel crisis, because it is an afterhours scandal that involves the cover-up of sexual assaults by the coaching staff and the release of players and coaches. 


\section{Crisis Communication}

Crisis communication is a key part of the crisis management process and public relations as a whole. Several scholars have proposed crisis communication theories and strategies that can be employed by organizations facing a crisis to help mend its reputation and relationship with its stakeholders. An organization's reputation is defined based on how well the company is meeting the audiences' expectations based on its prior actions (Coombs, 2007). When a scandal occurs, the organization(s) involved tend to face many consequences, including a tarnished reputation. Here, I examine Benoit's image repair theory, Coombs' situational crisis communication theory and two additional diversion strategies.

Image repair theory. Benoit's image repair theory (1997) focuses on communication strategies that organizations can use when faced with a crisis rather than the types of crises or stages of a crisis. It is assumed that an organization is responsible for an undesirable action, and that they must use different strategies to repair their reputation. Further, the strategies used by an organization should directly correlate with the audience it is trying to reach. It is imperative that an organization has identified its audiences prior to commencing crisis communication.

Benoit (1997) posits five different categories that crisis communication strategies fall under: denial, evasion of responsibility, reducing offensiveness, corrective action and mortification. Denial, as the name suggests, is when the organization either simply denies that it had anything to do with the crisis or it 
shifts the blame onto another actor in the crisis. Evading responsibility can occur through four different strategies: provocation, defeasibility, accident or good intentions. The first, provocation, is used by a company when it says it responded to another organization's offensive act. Defeasibility is when the business claims that it had a lack of information or control over the situation. The third strategy is used when the company suggests the action that led to the crisis was merely an accident. The final strategy in this category is used when an organization stresses that the actions the organization took were with good intentions. An organization will use these strategies when it is attempting to distance itself from the offensive act (Benoit, 1997).

Under Benoit's third category, an organization can work to reduce the offensiveness of an event through six different communication strategies. The organization can bolster itself to get its audiences' attention back on the good traits of the company. A business can try to minimize the act by saying it isn't as serious as it may be coming across. A company can differentiate its actions from a more offensive action that could have occurred. When an organization argues that there are more important things to consider and it is trying to place a crisis in a more favorable light, it is using the strategy of transcendence. Another way an organization can reduce offensiveness of its actions is by attacking the accuser in attempts to reduce the attacker's credibility, and lastly, the company can compensate those who were affected in some way. When organizations are employing these strategies it is trying to lessen the perceived wrongdoing. When an organization promises a solution to the problem it is using the strategy of 
corrective action. The last strategy identified in Benoit's (1997) image repair theory is mortification, which is when an organization issues an apology.

Situational crisis communication theory. Coombs' (2007) situational crisis communication theory (SCCT) focuses on crisis responsibility. SCCT aims to understand how the audience perceives a crisis and the crisis communication strategies employed by the organization. In order to determine this, the organization must first understand how the audience categorizes the crisis. Unlike Benoit's (1997) image repair theory, Coombs' (2007) theory focuses on the type of crisis. Coombs provides three different categorizations for crises: victim, accidental and intentional. Baylor faced a crisis that could be categorized as intentional, because it was also preventable. If a crisis is intentional it means an organization knowingly took actions that led to people being at risk or violated regulations or the law. Next, the organization's reputation and crisis history has to be considered, because such information could impact the degree of responsibility an organization has for a scandal, which will impact how the company communicates during the crisis at hand. Once the type of crisis and organizational history has been considered, an organization can determine what crisis response strategies to use (Coombs, 2007).

Coombs identifies both primary and secondary response strategies. Primary response strategies include attack the accuser, denial, scapegoat, excuse, justification, compensation and apology. Many of these strategies overlap with what Benoit presented in his image repair theory. Here, denial, attack the accuser and compensation are all the same as in Benoit's theory. 
Although the nomenclature is different, justification, scapegoat and apology are also included in image repair theory. Justification aligns with minimization, scapegoat aligns with shifting the blame, and apology aligns with mortification. Excuse is a combination of defeasibility and good intentions. It is where the organization tries to minimize the severity of the crisis by saying harm wasn't intended or they lacked control over the situation (Coombs, 2007).

The secondary response strategies presented in situational crisis communication theory include reminder, ingratiation and victimage (Coombs, 2007). Reminder is the same as bolstering in image repair theory, because the focus is shifted to the good characteristics and actions of the organization. Ingratiation is employed when an organization praises the stakeholders. Lastly, victimage is when organizations remind its audiences that it is also a victim of the undesirable action or event (2007). The strategies of reminder, ingratiation and victimage are used to help offset the negative response to the current crisis at hand. Although there are several of the same or similar strategies in Coombs' and Benoit's theories, they have both been included in this study because there are different strategies presented that may emerge while studying the Baylor sexual assault scandal.

Diversion. Bruce and Tini (2008) studied the Canterbury Bulldogs' cheating and salary cap scandal. They used textual analysis of media coverage to examine the crisis communication strategies being used by the team. They found that the Bulldogs seemed not to understand best practices when it comes to public relations and crises. The team used denial, attack the accuser, 
provocation, scapegoat, corrective action and mortification, but they were not successful in using these strategies, which caused the organization to lose complete control over the scandal and its reputation. The researchers did find that the Bulldogs were moderately successful with one communication strategy they coined diversion, which has not been addressed in any other crisis communication theory. Diversion, in this case, is when a sports organization focuses on how a scandal is negatively affecting the players and fans that are innocent victims of the crisis. Bruce and Tini's (2008) diversion strategy has been included in this study to see if it is a strategy used by Baylor and its fans during the sports scandal.

Brown and Billings (2013) also identified a diversion communication strategy employed by University of Miami fans. In this study, Brown and Billings did a content analysis of University of Miami fans' tweets to examine how they acted as crisis communicators. They found that fans used different crisis communication strategies, and that the frequency of these strategies changed over time. They also uncovered a new diversion strategy that isn't addressed in Coombs' or Benoit's theories. In this study, they found that fans were diverting attention away from the crisis at their school and onto problems that other schools were facing. Brown and Billings' (2013) diversion strategy is included in this study to see if this strategy is used during other sports scandals, specifically the crisis at Baylor University. 


\section{Social Media}

Social media are platforms "that enable consumers to connect, communicate, and collaborate with others" (Wallace, Wilson, and Mitoch, 2011, p. 424). Social media platforms are unique compared to traditional media for many reasons. First, social media sites allow and encourage interaction, whereas traditional media only support one-way communication (Sanderson and Hambrick, 2012). Also, social media tools help speed up communication by allowing organizations to disseminate information to their followers quickly (Gibbs and Haynes, 2013; Ott and Theunissen, 2015; Siah Ann Mei, Bansal and Pang, 2010; Storm and Wagner, 2015; Wang and Zhou, 2015). Traditional media can be quick when it comes to breaking news, but social media are quicker. Social media allow individuals to create and comment on breaking stories as soon as they happen. Individuals no longer have to wait for the evening news to learn about something that happened during the day. Further, social media allow for more voices to weigh in on the conversation. Lastly, social media give the power to demand and share information to the consumer, which they have readily adopted. Instead of passively waiting for information through traditional media like in the past, people today actively seek out information online and expect to instantly receive information (Stephens and Malone, 2009; Sutera, 2013).

Although traditional mass media may seem to be at odds with social media, many traditional platforms have recognized the value of social media and have figured out a way to incorporate social media into their operations. Many news organizations, both those that report on many topics and those that are 
specific to sports have found a way to incorporate social media like Twitter into their marketing efforts. Twitter is a social media platform that allows users to exchange short, 140-character messages with their other Twitter users, including their followers and organizations ("Getting started with Twitter, n.d.). As a platform, Twitter prides itself on "offer[ing] simplicity in a world of complexity" (Gaudin, 2011).

The simplicity of Twitter makes it ideal for traditional media sources to incorporate into their operations. For example, ESPN uses Twitter in their various programming to give the fans some control over conversations taking place. Twitter makes it easy for ESPN to incorporate fans' opinions because the tweets are short, which force the user to get to the point. Further, hashtags make it easy for an organization to track conversations taking place, and are often used when tweeting during a live event. Lastly, frequent posts are encouraged on Twitter, but frequently posting about the same topic on Facebook may irritate an individual's followers and warrant a warning from Facebook for posting too often (Sutera, 2013). For these reasons, Twitter is the perfect social media site to converse about sports.

It is important that sport-specific news organizations are on social media, because it will allow them to reach more people and listen in on conversations between sports fans and teams. Brown (2014) found that college students used Twitter as their primary social media outlet to frequently gather news about sports. Knowing where fans learn about sports-related news allows news organizations like ESPN to deliver the news to them first. Understanding how 
individuals use Twitter to gather sports news, including scandals, is important to this study, because Twitter is where the conversation begins.

Twitter became popular in the world of sports early on. According to Sutera, athletes were some of the first celebrities to really leverage the power of Twitter, which enticed fans to also be on Twitter (2013). Fans realized that Twitter helped close the virtual gap between them and their favorite athletes and teams. Nowadays, social media is so prevalent in society that if you lack a social presence you may be considered abnormal (Sutera, 2013). With an estimated $63 \%$ of Twitter users in the United States getting their news from Twitter, it has become an important communication tool during sports scandals (Desilver, 2016).

The literature on crisis communication theories and strategies, as well as social media have led to the development of the first research question, which will be answered through a textual analysis and presented as a case study.

$R Q$ 1a: What crisis communication strategies did Baylor University use on Twitter as the football sexual assault scandal was uncovered between 2015-2017?

\section{Social Media and Crisis Communication}

Due to the power social media gives individuals to weigh in on conversations and request information, scholars have started to address how social media should be used in the crisis management process. An organization is irresponsible and is hurting itself if it chooses to ignore social media during a crisis. Veil, Buehner and Palenchar (2011) created a list of social media best practices for the crisis management process. These best practices include: 
- adding social media to the existing crisis management plan and policies;

- using social media to listen to stakeholders concerns;

- building a relationship on social media prior to a time of crisis;

- showing individuals you care by interacting with them on social media;

- sharing accurate and honest information; sharing messages with credible sources;

- recognizing that traditional media will be part of the discussion on social media;

- humanizing the organization's voice on social media; using social media as an updating tool;

- providing direction for stakeholders;

- and remembering that social media are important tools, but the impact of the communication relies on the quality of the content shared.

Lin, Spence, Sellnow and Lachlan (2016) have also created a list of social media best practices that communicators can refer to during the crisis management process. This list includes many of the practices identified by Veil et al. (2011), but also includes the following principle: if you promote a hashtag, police it. A hashtag is a great way to monitor a conversation, but if left unmonitored it can veer off into a land of rumor mills (Lin et al., 2016). These social media best practices identified by Veil et al. (2011) and Lin et al. (2016), as well as the crisis communication recommendations identified by Benoit (1997) and Coombs (2007), have led to the development of the second research question.

$R Q$ 1b: How did Baylor University's communication strategies on Twitter compare to crisis communication and social media best practice recommendations during the 2015-2017 sexual assault scandal? 


\section{Sports Fans}

Identifying with their favorite team plays an important role in a sports fan's life (Wann, Melnick, Russell and Pease, 2001). The extent to which and the way a fan identifies with their favorite team can vary between fans. However, loyal fans are those who, in some way, identify with and have an attachment to the team or athletes (Kang, 2015; Wu, Tsai and Hung, 2012). Understanding the role a sports team plays in the life of a fan can help explain why fans do the things they do. The actions fans take may speak to the fact that most fans want to receive recognition for their devotion to their favorite team and athletes (Sutera, 2013). Actions a fan may take include attending sporting events, purchasing team gear and communicating with or on behalf of a team. Communicating with or on behalf of a team is particularly important during a sports crisis. Brown (2014) found that during a sports scandal, "fans are more likely to engage in...fan-enacted crisis communication behaviors using online platforms" (p. 101). By understanding what motivates a fan to act on behalf of a team, practitioners can leverage this relationship to their benefit during a sports scandal.

Media, in general, play an important role in sports fandom (Kang, 2015). Media helps give fans access to their favorite teams and players. Pertinent to this study is the fact that fans often express their loyalty to a team through social media (McClung, Eveland, Sweeney and James, 2012). The use of social media allow fans to engage with one another and with teams and athletes, which in turn leads to mutual identity building, which further aids in strengthening their bond as a fan (Scholl and Carlson, 2012). Additionally, social media allow the average 
citizen to contribute as an active voice in sports (Sutera, 2013). Before social media, fans would go to drastic measures to be recognized for their voice in sports, like streaking the field, but with social media it is much easier for fans to contribute to conversations and be noticed.

\section{Sports Fans as Crisis Communicators on Social Media}

Brown (2014) conducted a study to understand the effects of fan-enacted communication online. She examined how fan association, crisis type and crisis strategy affected different attitudes and behaviors such as fan-enacted crisis communication. In her study, she only incorporated three of Coombs' (2007) crisis communication strategies: ingratiation, reminder and attack the accuser, which could have limited her findings. Her results show that fan identification, which is "the extent to which a fan feels a psychological connection to a team and the team's performances are viewed as self-relevant" (Wann, 2006, p. 332), is an important indicator as to whether an individual will speak on behalf of an organization during a scandal (Brown, 2014).

Brown (2014) also found that with the limited amount of characters, it could be challenging to successfully use Twitter to employ one of the crisis communication strategies found in Coombs' situational crisis communication theory. Instead, she suggested that future research look to see if new, modified crisis communication strategies are being employed in online communication. Additionally, Brown (2014) recommends that future studies incorporate more of the crisis communication strategies outlined in Coombs' (2007) situational crisis communication theory. This study includes relevant strategies from both 
Coombs' (2007) and Benoit's (1997) theories, as well as two additional strategies identified in sports-related crisis communication research. Lastly, Brown (2014) notes that future research should examine how fan-enacted crisis communication strategies compare to those of the organization.

Brown and Billings (2013) recognized the importance of Twitter in the sports community when they conducted their study about a scandal at the University of Miami. Using content analysis, they sought to understand how fans used Twitter during a NCAA investigation involving a scandal. Prior to conducting their study, Brown and Billings (2013) noticed that crisis communication scholars "ha[d] yet to address whether a community can utilize social media to act on behalf of a company or organization-especially one in which they have a major investment, such as their alma mater or current institution of higher learning" ( $p$. 76).

Brown and Billings' (2013) results showed that fans were indeed discussing the scandal on Twitter, and that they were acting as crisis communicators on behalf of their team. Nine of the strategies used by fans in their study are ones identified by Coombs in the situational crisis communication theory. These strategies included attack the accuser, denial, scapegoat, excuse, reminder, ingratiation, compensation and apology. The tenth strategy was a diversion strategy unique to this specific study. The researchers found that fans were diverting attention away from the scandal at the University of Miami and toward problems and scandals at other schools. This strategy has been included in the current study to see if it extends to a different school and scandal. Further, 
Brown and Billings (2013) found that the strategies being employed by fans changed over time as news about the scandal evolved.

Brown, Brown and Billings (2015) conducted a study on sports fans during the Penn State sexual abuse scandal. Using the lens of both Benoit's image repair theory and Coombs' situational crisis communication theory, the researchers sought to see if fans would communicate on behalf of their team, which was suggested by previous research, and which crisis communication theory best fit the strategies being used by fans. For this particular scandal, they found that Coombs' theory was more applicable to the strategies being used by fans, and suggested that Benoit's theory was more fitting for scandals involving an individual athlete. That being said, both theories are incorporated into this study to see if the suggestion made here applies to a different organizational scandal.

Surprisingly, the results from Brown et al. (2015) showed that fans turned against the university, and instead showed their loyalty to Coach Joe Paterno. These results are surprising because previous studies show that fans will use strategies in defense of university decisions rather than against it. Fans used scapegoat, ingratiation, reminder, victimage and compensation strategies in favor of Coach Paterno. This study is the first to demonstrate that online fan-enacted crisis communication can be used to demean the decisions made by a university, which is against its best interests and can alter the crisis communication strategies used by that organization. It will be interesting to see if Baylor fans acted in a similar manner as Penn State fans by using crisis communication 
strategies that demean the university for its decisions rather than fully supporting the university and athletic program during the scandal.

This thesis looked at what crisis communication strategies Baylor fans used during the sexual assault scandal that unfolded between 2015 and 2017. Unlike similar studies in the past, the present research involves a qualitative study. Further, this study hopes to expand on the findings of Brown and Billings' (2013) and Bruce and Tini's (2008) studies by looking for the use of diversion, both onto other scandals and onto innocent groups being affected by the actions of others. Taken together, this literature and research helped to develop the second research question.

$R Q$ 2: What crisis communication strategies did Baylor University fans use on Twitter as the football sexual assault scandal unfolded between 2016 and 2017? 


\section{Chapter 3: Methodology}

\section{Summary}

The purpose of this study was to understand how Baylor University and its fans used crisis communication strategies during the football sexual assault scandal that unfolded between 2015 and 2017 . Sports fans are typically considered an audience of a sports organization, but they can act as a pseudointernal member of the organization by employing crisis communication strategies on behalf of the organization during a scandal. The power of social media gives fans the opportunity to act as crisis communicators on behalf of their organization, which can shape the conversation going on online.

This study looked specifically at the Baylor University football sexual assault scandal as it unfolded between September 2, 2015 and February 3, 2017. Previous studies have looked at how sports fans have acted as crisis communicators during a NCAA investigation. Studying sports scandals under NCAA investigation has worked well, because per NCAA rules, teams involved in an ongoing investigation are not allowed to comment on the investigation (NCAA, 2016). Being unable to comment on an ongoing investigation can leave an organization defenseless regarding crisis communication, but this is where fans can step in.

Unlike these previous studies, this study aimed to look at how Baylor University and its fans acted as crisis communicators during a sports scandal that wasn't under a NCAA investigation. By studying a sports scandal that wasn't 
under NCAA investigation, this study was able to tap into how fans acted as crisis communicators on when their team has the capability of enabling their own crisis communication strategies. Understanding how fans can act on behalf of a team during a scandal can help practitioners leverage these communicators to fit the best interests of the organization during a crisis.

In order to examine how Baylor University was communicating during the crisis, a textual analysis of tweets was conducted. The results for the first research question are presented in the form of a case study. What's unique about the Baylor scandal is that Baylor is not saying much. In the occasional instance when Baylor comments on the scandal, the tweets seem "hidden." For example, the school released a press release on Twitter about the internal investigation right before the 2016 Super Bowl started. In this instance, there was a lot of Twitter activity focusing on the game, making it easier for the university's tweet to get lost. This scandal is also unique compared to other ongoing sports scandals, because although the NCAA did not launch a formal investigation, the Big 12 Conference has inquired about Baylor's internal investigation and the United States Department of Education launched a Title IX investigation into Baylor's handling of sexual assault. Further, Baylor is the largest Baptist University in the world, which has drawn further criticism to its handlings of sexual assaults. Along with the timeliness of the scandal, these reasons are why the Baylor sexual assault scandal was chosen as the scandal of study. 
In order to answer the second research question, the researcher will use a textual analysis of tweets to identify what Baylor fans used crisis communication strategies.

\section{Rationale}

This study starts with a textual analysis of Baylor's communication on Twitter, and is presented in the form of a case study in order to understand how Baylor has handled the scandal. According to Yin, as cited in Baxter and Jack, a case study allows the researcher to contextualize the event being studied (2008). In this case study, the researcher examined Baylor's communication on Twitter during the scandal and how it compared to what is recommended by crisis communication and social media scholars. Following the case study, the researcher will move into the second phase of research: a textual analysis of fans tweets.

Next, this study used textual analysis to understand how fans of Baylor University used Twitter to communicate on behalf of the university, football team and athletic department during the 2015-2017 sexual assault scandal. Textual analysis is a research method that allows the researcher to "make an educated guess at some of the most likely interpretations that might be made" of the texts being studied (McKee, 2003, p.1). Once texts were collected the researcher coded the texts to identify patterns and to interpret the meaning of the texts. Coding texts involved using "a word or short phrase that symbolically assigns a summative, salient, essence-capturing, and/or evocative attribute for a portion of language-based" data (Saldaña, 2013, p. 3). Fans tweets were coded in order to 
identify the crisis communication strategies they used throughout the investigation of the scandal.

In opposition to other research methods such as interviews or focus groups, textual analysis allowed the researcher to gain more insight into how Baylor's fans used Twitter during the 2015-2017 Baylor football team's sexual assault scandal. By using textual analysis, the researcher was able to study the tweets and identify what themes emerged from the text. It is assumed that fans did not consciously or knowingly use crisis communication strategies that are often used by public relations practitioners in their tweets. By focusing on the texts, the researcher was able to understand the crisis communication strategies used by Baylor's fans.

\section{Collection}

For the case study, collection of data began with tweets from Baylor University (@Baylor), Baylor Athletics (@BaylorAthletics) and Baylor Football (@BUFootball) Twitter accounts. In order to understand how Baylor communicated during the scandal on Twitter, the researcher conducted an advanced search of tweets sent out by the Baylor accounts between September 2, 2015 and February 3, 2017 (See Appendix A). From this she pulled the tweets relating to the scandal. In order for a tweet to qualify as relative to the scandal, the tweet must have in some way addressed the allegations, investigation into or the principle parties involved in the scandal. The allegations include sexual assault and the investigation includes the internal investigation done by Pepper Hamilton, the Big 12 Conference inquiries and the United States Department of 
Education Title IX investigation. The key parties include Art Briles, Ken Starr, lan McCaw, Sam Ukwuachu, Shawn Oakman, Tevin Elliott, Colin Shillinglaw, Tom Hill, Jasmin Hernandez, Devin Chafin, Dolores Lozano, Bob Bowlsby, Mack Rhoades, Jim Grobe, Brenda Tracy and Patty Crawford. Additionally, tweets that bolstered Baylor's image were also collected, because these tweets represented a crisis communication strategy used to offset some of the negative emotion associated with the crisis. Additionally, it's important to note that only tweets that contained original content from each account were collected. For example, @BaylorAthletics retweeted several of @BUFootball's tweets without adding any other text. Because these tweets were collected from @BUFootball they were not collected a second time from @BaylorAthletics account. Once these tweets were identified and collected the researcher conducted a textual analysis and used this information for the case study. Next, the researcher focused on identifying tweets from Baylor fans.

Figure 1

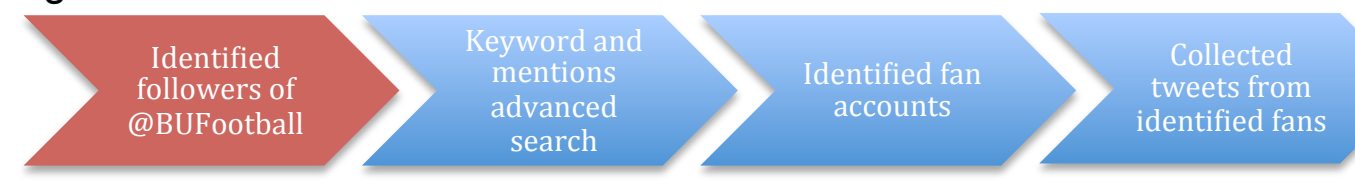

Initially, this study hoped to include data from both Baylor fans and $@ B U F o o t b a l l$ followers that did not self-identify as Baylor fans. It was postulated that because this scandal largely focused on the football team, those who follow the football team would likely weigh in on the conversation. In order for a follower to be included in this study, they needed to identify as a sports fan and could not identify as a journalist or a fan of a rival school in Texas or the Big 12 Conference. However, as the researcher collected this data, many technical 
issues came up. First it was very challenging to get through the vast amount of @BUFootball followers. Twitter would reset the follower list semi-frequently, which required the researcher to scroll through all of the followers she had already gone through. Second, because the scandal was ongoing during the data collection, @BUFootball gained over 5,000 new followers during the first four weeks of the data collection process. This made it challenging for the researcher to get through to the followers who had been following Baylor since the beginning of the scandal. Lastly, the researcher hit a point where the follower list would no longer load. She kept the usernames of the followers she had found; however, none of these individuals had tweets that showed up during the collection, so ultimately the followers who did not self-identify as a Baylor fan were not included in the study.

To compensate for these issues and identify fans of Baylor, the researcher did an advanced keyword search using Twitter's advanced search function (https://twitter.com/search-advanced) to identify tweets relating to the scandal. The advanced search function made it easy for the researcher to identify tweets that related to the scandal by filtering for source, keywords, hashtags, and timeframe. The researcher searched hashtags such as "\#BaylorScandal" and "\#TruthDontLie" and keywords like "Baylor," "Briles" and "Title IX" during key dates of the scandal between January 31, 2016 (the date Outside the Lines released the initial report accusing Baylor of mishandling sexual assaults) and February 3, 2017 (when information about former Coach Art Briles' text messages was released). A complete list of dates and keywords searched can 
be found in Appendix B. From this, the researcher individually checked every Twitter profile she came across. A list of Baylor fans was kept and referred to during the collection process. To qualify as a Baylor fan, a user needed to textually or visually identify as a Baylor fan in their profile photo, cover photo, bio or tweet.

Lastly, once it was determined that a tweet was sent by a self-identified Baylor fan, that tweet was collected. If the tweet was part of a series of tweets that did not all show up in the initial advanced search, the researcher did an advanced search of that fan's profile to find all of the relevant tweets. It's important to note that the researcher only had access to tweets that were sent by fans with a public profile or fans that the researcher already followed during the collection process. Additionally, the account still had to exist on Twitter during the data collection for the researcher to have access to tweets relating to the scandal.

\section{Instruments}

When tweets were identified the researcher took a screenshot, which was cataloged by week for the university tweets and by date for the fan tweets. These tweets were numbered and stored in both a folder and a document. After reviewing multiple tweet collection tools, it was determined that although this was a time-consuming method to gathering tweets, it was the only way the researcher could identify tweets from fans relating to the scandal within the designated time frame and on key dates of the scandal. Although some collection tools can 
gather all of this information, the researcher lacked programming knowledge that would be needed to utilize these tools.

The researcher chose to analyze all of the tweets collected during the timeframes set for both Baylor University and its fans. Initially, the idea of using a random number generator was considered, however, the volume of tweets gathered from Baylor was already limited because the university chose not to say much about the scandal during the timeline. Additionally, because fan tweets were gathered on key dates over the course of the scandal timeline rather than over the entire course of the scandal it made the number of tweets gathered a manageable amount to analyze.

\section{Rigor}

To enhance the validity of this study, I, the researcher critically reflected on how I could be impacting the study. Reflexivity is "the process of a continual internal dialogue and critical self-evaluation of researcher's positionality as well as active acknowledgment and explicit recognition that this position may affect the research process and outcome" (Berger, 2015, p. 220). Although I do not identify as a Baylor University fan, I consider myself to be an avid sports fan, especially of competition in the Big 12 Conference. I also carried an opinion about the allegations made against the Baylor football program. Acknowledging these potential biases allowed me to avoid them affecting the analysis and results of my study.

Recognizing that I had potential biases was the first step in the reflexive process. As I moved through the data collection and into the analyzing phase of 
the research, I consciously reflected on how my feelings toward the Big 12 Conference, sexual assault on college campuses and the Baylor scandal was affecting my ability to analyze the texts in an unbiased way. If I ever feel like my biases were getting in the way of the integrity of my research, I stepped away from the texts until I had enough time to reflect and could approach the texts with my biases in check.

\section{Data analysis}

This study used a grounded theory approach to allow flexibility in the research design and to allow the data to lead to the theory instead of forcing data into a theory (Connelly, 2013). Constant comparative analysis was used, because it allowed the researcher to start with conceptual categories they expected to emerge from the data, but gave them the freedom to redefine these themes based on what emerged from the data (Glaser and Strauss, 1967).

The codebook for this study, which can be found in Appendix C, included the different crisis communication strategies outlined by Coombs (2007) and Benoit (1997). In Coombs' situational crisis communication theory it is assumed that there are different communication strategies an organization should use depending on how the attribution of the crisis at hand can be classifiedaccidental, victim, or preventable (2007). In Benoit's image repair theory, it is assumed an organization is responsible for an undesirable action, and it must use different strategies to repair its reputation (1997). The additional diversion strategies proposed by Bruce and Tini (2008) and Brown and Billings (2013) were also included. 


\section{Chapter 4: Findings}

This study used textual analysis to understand how Baylor University and its fans communicated on Twitter during the sexual assault scandal that unfolded between 2015 and 2017. Once tweets were collected, the researcher went through the tweets and noted which communication strategies were being used, while continuously referring to the codebook and the tweets already coded. The researcher then went through the tweets again to identify what communication strategies were being used the most and how they were being used. Lastly, the researcher combed through the data again to find tweets that exemplified the conclusions reached in order to include them as examples in the findings. The tweets used as examples can be found in Appendix D (Baylor's tweets) and Appendix E (fan tweets).

While examining Baylor's three Twitter accounts there were differences in both the crisis communication strategies used and the frequency of use between the accounts, but overall, two crisis communication strategies were used most frequently: corrective action and bolstering/reminder. Additionally, Baylor University introduced a religious approach to crisis communication, which is not commonly seen at the university level in crisis communication.

While examining fans' tweets, seven crisis communication strategies emerged: scapegoat/shift the blame, diversion as proposed by Brown and Billings (2013), attack the accuser, victimage, differentiation, bolstering/reminder and ingratiation. Additionally, fans employed Brown and Billings (2013) strategy 
of diversion in ways that are unique to this study. First, the fans used it to specifically divert attention to another school and to broadly divert attention to many universities at once. Second, fans used diversion to focus on previous Baylor scandals and actions. Lastly, it's important to note that some of the fans' tweets only employed one strategy while other tweets employed multiple strategies.

The findings for the first research question that focused on Baylor University's communication are discussed first. They are described with the crisis communication recommendations given by Benoit and Coombs, and with the social media best practices in mind. Next, the findings for the second research question that focused on fan communication are discussed. The analysis is described with crisis communication strategies and previous fan-enacted crisis communication research in mind.

\section{Baylor University}

On September 2, 2015, Baylor University announced it had hired Pepper Hamilton Law Firm to conduct an investigation into how the university handled sexual assault allegations. A few months later on January 31, 2016, Outside the Lines (OTL) aired a report claiming Baylor ignored sexual assault allegations against football players. After this, Baylor University found itself in the middle of a sexual assault scandal largely centered on the football program. Over the course of the scandal, Baylor did not communicate as efficiently and effectively as it could have, which is part of the reason the scandal was in the limelight for so long. 
For example, fans and critics alike became enraged with the university for dumping news before the 2016 Super Bowl and on holidays like Memorial Day and New Year's Eve. As cited in Walsh and Austin (2013), there are many reasons an organization may decide to dump news on holidays and weekends, including fewer reporters available to cover the news dump, hiding its bad news among the news dumps of other organizations and fewer individuals paying attention to the news on these days. By dumping news before the Super Bowl and on holidays, Baylor was most likely attempting to avoid scrutiny from individuals and the media (Walsh and Austin, 2013). This case study answers the first research question:

$R Q$ 1a: What crisis communication strategies did Baylor University use on Twitter as the football sexual assault scandal was uncovered between 2015-2017?

$R Q$ 1b: How did Baylor University's communication strategies on Twitter compare to crisis communication and social media best practice recommendations during the 2015-2017 sexual assault scandal?

Research. Tweets from Baylor University (@Baylor), Baylor Athletics (@BaylorAthletics) and Baylor Football (@BUFootball) accounts were collected between September 2, 2015 and February 3, 2017, and analyzed to help answer the first research question. The findings from each Twitter account will be examined individually and then evaluated as a whole in the next section.

It is important to note that unlike public, state-funded universities, Baylor University was able to take a religious stance during the scandal. This stance has not been seen often at the university level, because of the separation of state and church that public universities must adhere to. School administrators and 
teachers at public universities may not push a religious opinion or practices onto students ("Joint statement," n.d.). Baylor University, on the other hand, does not need to adhere to this because it is a private Baptist school. The religious stance is unique to this scandal compared to previously studied scandals at Penn State University, a public university (Brown et al., 2015) and the University of Miami, a private, nonsectarian school (Brown and Billings, 2013). The tweets used as examples in this section can be found in Appendix D.

Strategies. The two most commonly employed strategies by Baylor-run accounts were corrective action and bolstering/reminder. There were, however, differences in how frequently each account used these strategies. There were also differences in the strategies each account used.

@Baylor. The main account for the university employed the strategies of corrective action and reminder/bolstering frequently and was the only account to apologize for the scandal, albeit only once.

Corrective action. Although Baylor used corrective action, the content shared in the tweet characters, which is limited to 140 letters, numbers and symbols, was often vague and did not let stakeholders know specific actions that were being taken to rectify and avoid a similar scandal in the future. For example, on February 12, 2016, Baylor tweeted, "\#Baylor Regents approve action plan to prevent sexual violence on campus \& improve services for those impacted: bit.ly/1XoqibE[.]" Although this tweet included a link with more specific information, the content of the tweet did not contain examples of what was in the action plan. Additionally, this tweet did not contain a graphic, a tool that Twitter 
affords users that could have been used to share more specific details about the action plan.

On April 5, 2016, a tweet containing a religious frame while also promising corrective action was sent out by Baylor. The university tweeted, "\#BAYLOR NATION: Please join professors and students in pausing for a moment of prayer/reflection. \#SAAM \#ItsOnUsBU[.]" The tweet contained a graphic that contained four prayers for the university and community. One of the prayers demonstrated vague corrective action: "Pray for the wisdom of our leaders as they shape efforts to prevent interpersonal violence and care for survivors of sexual assault. [1 Timothy 2:1-2]" As mentioned, taking a religious stance during a university scandal is not something that has been commonly seen, because the schools that have so far been studied include a nonsectarian private school and a public university that cannot push religion onto its students. In this instance, citing religious values was a way for Baylor to enhance its use of corrective action as a communication strategy. By using a religious stance, Baylor was showing that, with the grace of God, they were going to be better and fix the problems that existed at the university.

Similarly, on August 23, 2016, the university tweeted, "Since June, \#Baylor has completed/made significant progress on over $3 / 4$ of sexual assault response recommendations: bit.ly/2bg9Ax8[.]" This tweet did not provide an example of what had specifically progressed or been completed. This tweet provided hope for fans that Baylor may be nearing the end of the scandal and may be living up to the standard they hold the university to, yet the university did 
not share specific information in the tweet. This tweet also lacked a graphic to help illustrate the changes or to engage fans in what could be considered good news.

Although the university was often vague at times in its communication, there were a couple of times when specific information was shared. On November 10, 2015, the university tweeted, "During National \#ItsOnUs Week of Action, join us in pledging to stop interpersonal violence: bit.ly/1NlojNO" along with the graphic associated with the week of action. This tweet was sent out a couple of months after Baylor announced Pepper Hamilton would be conducting an investigation into how the university handled sexual assaults, but before OTL released its report. This tweet used the communication strategy of corrective action by stating that the university is publicly pledging to stop interpersonal violence. Additionally, this tweet provided a call-to-action for fans and alumni to join the university in this pledge.

On June 29,2016 , the university addressed specific actions being taken in a series of tweets that contained information from a letter the university president sent out. One of which stated, "The \#Baylor Counseling Center is reducing wait times, limiting fees \& eliminating session limits: bit.ly/295b1hG (5/5)[.]" In this instance, the university was satisfying fans need to know what actions were being taken to correct the scandal and avoid a similar crisis in the future. They did this by providing specific actions the university was taking in regards to the counseling center. 
Reminder/bolstering. The university employed the strategy of reminder/bolstering to boost its image. In a chain of tweets sent out on June 29, 2016, Baylor shared, "\#Baylor is hiring additional counselors that will make our student-to-counselor ratio among the nation's best: bit.ly/295bqhG (4/5)[.]" This tweet combined both corrective action and bolstering, because the university addressed that was adding additional counseling staff, which would make the student-to-counselor ratios one of the best. By boasting about this achievement, Baylor was reminding its stakeholders that it was and will work to be an exemplary university, even though there is a serious scandal going on.

Similarly, Baylor used reminder in its December 30, 2016 tweet, "Thank you, Bears! Your love led to \#Baylor being named the nation's No. 1 university on Facebook \& No. 3 on Twitter! bit.ly/2ixTxLj" accompanied by a photo of the campus. The first phrase of this tweet shows an example of ingratiation being used by the university, which simply means it praised its students and alumni. The second part of the tweet was a reminder to Baylor Nation that it is a wonderful university and is recognized as such.

The university also used this strategy to recognize the many students that came together to volunteer in the Waco community. On November 15, 2016, Baylor tweeted, "This weekend, more than 2,000 students served the \#Waco community during \#Baylor's Steppin Out event: bit.ly/2fCFSRy \#BaylorServes" with an accompanying photo of students volunteering. This event had nothing to do with the ongoing scandal, but the tweet served as a reminder that Baylor Nation does good by giving back to the community. 
Apology/Mortification. During the scandal, the university only apologized in a tweet once. On June 4, 2016, the day after a PR expert ended an interview Ken Starr was doing because he stated he might have seen an email titled 'I was raped at Baylor,' the university tweeted, "\#Baylor: 'We are deeply sorry for the harm that survivors have endured." This tweet also contained a screenshot of a letter sent by President Garland to the Baylor community. By apologizing the university was recognizing the harm done to the victims and working to rebuild its reputation.

@BUFootball. The football account primarily used bolstering/reminder to boost its image during the scandal, but also employed the strategy of corrective action.

Bolstering/reminder. The football program used this strategy to demonstrate how the players gave back to the community as well as how Baylor was a good place to be. For example, on December 26, 2015, @BUFootball tweeted, "Hula hoop game strong as players visit with terminally ill children." A photo of the event accompanied the tweet. Similarly a few months later, on April 27,2016 , the football program tweeted, "Bears hard at work, giving back to the Waco community. \#SicEm" with a photo of a player painting a house. Again, on January 16, 2017, they tweeted, "This morning players joined with other Baylor students to honor the \#MLK legacy by volunteering their time as part of \#MLKDayofService" with photos of the players volunteering. All of these tweets served as a reminder to how great the football program was and the ways in which the players gave back to the Waco community. By focusing on the ways 
the football players gave back to the community, the program was trying to repair its image and reputation.

Bolstering was also used to reiterate what a great place Baylor was. On December 7, 2016, the team tweeted, "'It's not often in life that you get off a plane in a new place, and say to yourself 'Oh, this feels like home.' \#SicEm [football emoji]" with a video of Coach Rhule, who was hired to replace Art Briles and interim Coach Grobe, greeting the Baylor Family. By choosing this quote of Coach Rhule's to share, @BUFootball was reiterating the good qualities of the Baylor community and the athletic department by implying it's welcoming and a great place to be. By reminding fans of this feeling, they were trying to boost their image.

@BUFootball also took a religious stance, much like the university did. For example, on December 7, 2016, "[praise emoji] [praying emoji] \#SicEm" with a graphic containing this quote, "What a wonderful, fabulous, glorious day it is. God is great! He absolutely rules.' - Athletic Director Mack Rhoades" This tweet was in reference to the hiring of the new coach, Matt Rhule. Here, Mack Rhoades credited God for helping to make wonderful things, like the new hire, happen at Baylor. This can be considered bolstering because it reminded fans and alumni of the good action the program took by hiring Coach Matt Rhule. By coupling bolstering with a religious stance, Baylor was crediting God with the good changes happening at the university. Additionally, by praising God, this could have been the university's way of trying to convey that although there were 
sinners at the university, they will be forgiven, and the university is moving on to bigger and better things.

Corrective action. The football program used corrective action, but not nearly as frequently as the university. This was likely because the program did not want to portray the scandal as just a football team issue; rather it was a university-wide issue. @BUFootball used corrective action in regards to new hires and to acknowledge that players discussed sexual assault prevention. On June 3, 2016, they tweeted, "I felt led to be here. A situation where I could not only coach football, but be part of the solution and help these kids.' - Coach Grobe" Here, this quote illustrates how interim Coach Grobe was part of the changes and solution that Baylor needed to move past this scandal. By acknowledging that he wanted to fix the issues facing the football program, the football Twitter account is employing the communication strategy of corrective action.

In another instance, @BUFootball discussed how the football players were trying to make changes. On July 25,2016 , they quote tweeted, which is a retweet accompanied with added commentary, a tweet from @brendatracy24 that stated, "Huge thanks to all of the @Baylor players who have tweeted me. I appreciate you \& remember the pledge you made to each[ ]other! \#ItsOnUs[.]" In their tweet, the football program said, "Thanks for the important message, Brenda[.]" By acknowledging the pledge the players made and the importance of the pledge, the football program publicly committed to making changes to better the program, 
school and community. This tweet showed fans that the team was making an effort to be more educated and to be better in the future.

@BaylorAthletics. The athletic department account was largely silent about the scandal during the timeline studied. Most of the content tweeted out by the athletic department were retweets from all of Baylor's sport-specific accounts. The athletic department did craft a few tweets, mostly about the new hires within the football program. The tweets discussing the new hires could be classified as corrective action because it is a step the department took to fill the vacancies that were created when they let go individuals who were involved in the scandal. The athletic department also used Bruce and Billings (2008) strategy of diversion when they focused on the innocent players who had been adversely affected by the scandal but remained loyal to the program. Contrary to the university and football account, Baylor Athletics did not employ a religious stance in its tweets.

Corrective action. On December 7, 2016, Baylor Athletics tweeted, “Baylor's other head coaches stopped by to welcome @CoachMattRhule to @BUFootball. \#SicEm" and accompanied the text with images of Matt Rhule meeting the other coaches. This tweet very matter-of-factly stated that the other head coaches welcomed Coach Matt Rhule to the university. By not indicating that this was a good move for the football program, this tweet largely evokes the communication strategy of corrective action rather than bolstering/reminder. Had they shifted the focus to the good characteristics and actions of the program, this tweet would have been classified as bolstering/reminder. This tweet exemplifies 
corrective action because a new hire was necessary to move forward and get the football program back to not only winning but also operating in an ethical manner.

Diversion. About a month later the athletics department quoted Coach Matt Rhule in its January 27, 2017 tweet, ''We are not who they say we are,' Rhule said. 'We are who we are. The guys who stay and move forward will be remembered for a long time."” A CBS Sports article summary card accompanied this tweet. The specific quotes chosen by the athletic department indicate that it focused its attention on the innocent players who were affected by the scandal and chose to remain at the university even though they had every reason to leave. This is an example of diversion as proposed by Bruce and Tini (2008), rather than victimage because attention was focused on individuals within the program rather than portraying the whole program as a victim.

Crisis communication best practices. In crisis management "perceptions are more important than reality," which is why good communication during a scandal is so important (Benoit, 1997, p. 178). According to crisis communication scholars, there are some things that Baylor did well in its communications throughout the scandal and some things that could have been done better.

Situational crisis communication theory. As stated in the literature review, Coombs (2007) would define the sexual assault scandal that plagued Baylor between 2015 and 2017 as an intentional crisis, because there was management misconduct that was preventable. In this situation, the misconduct led to horrific acts that, once exposed, posed a huge threat to Baylor's reputation. 
Because of this and Baylor's crisis history, Coombs' (2007) theory recommends that the university should have used rebuilding strategies, which includes apology and compensation. Bolstering strategies, on the other hand, should have been used to supplement the rebuilding strategies in its communications. All three of the Baylor Twitter accounts included in this study did the inverse of what Coombs recommends by only apologizing once and using the strategy of reminder more frequently. The result of this led to some fans feeling like the university did not care about the victims as much as it cared about its image and athletics. This notion is evidenced in some of the fan tweets analyzed.

Image repair theory. On the other hand, Benoit (1997) recommends that organizations at fault should admit it immediately, which often conflicts with a program's desire to avoid lawsuits. Initially, Baylor's communications were focused on the internal investigation that was being conducted, but the university did not directly admit fault in how its Title IX office and football program were being operated. Fault was implied when Baylor started tweeting out actions they would take to do better and when the media uncovered more cases of sexual assault.

Benoit (1997) also notes that in a scandal where the organization is to blame it is important that they publicize the actions being taken to resolve the problem and avoid it in the future. Although stakeholders want to know whom to blame, they also want to know that corrective actions are being taken. It was smart for the university to use corrective action as a communication strategy because the scandal was of a serious nature and the university shared in the 
blame. However, although Baylor used corrective action, the information shared within its tweets was often vague, and the tweets themselves did not contain an additional graphic or video to help further explain the changes being made. This is problematic, because fans want to know what specific corrective actions are being taken to fix the problem and avoid a similar issue in the future, and many will not click on a link for news updates. In fact, research has shown that less than half of Twitter users will click a news link in a tweet and if they do click on the link it is usually from a tweet shared by a "regular" Twitter user rather than an organization (Dewey, 2016; Lee, 2016; Matsa and Lu, 2016). By relying on the assumption that fans would click a link in a tweet, Baylor ran the risk of fans being misinformed.

An easy way Baylor could have provided more information would have been through the use of an image, which the university used in other tweets. By creating a graphic with summary points of the corrective actions being taken, fans would have had a better idea of what was being done. Research also shows that tweets with images or summary cards have higher engagement compared to tweets with neither (York, 2017). By excluding a visual of some type, Baylor ran the risk of individuals scrolling right past the tweet without noticing or engaging with the tweet. In crisis management, this practice is not ideal, because an organization should want to frame the message rather than relying on the media or individuals to frame communication about the scandal. Additionally, by creating engaging tweets, Baylor's message could have reached more people. 
Lastly, Benoit (1997) acknowledges that it is okay and often wise to use multiple crisis communication strategies throughout the crisis management process. All three of the Baylor accounts used multiple communication strategies throughout the crisis management process. @Baylor utilized bolstering/reminder and corrective action most frequently and was the only account to use apology. @BUFootball primarily used bolstering/reminder and corrective action, and the athletic department employed the strategies of corrective action and Bruce and Tini's strategy of diversion (2008). Although Benoit (1997) acknowledges that using multiple crisis communication strategies is often wise, it is important that the strategies most appropriate to the crisis at hand are used, and used wisely. During the scandal, Baylor's communication could have benefited from incorporating different strategies into its communication, such as apology and compensation. Further, bolstering/reminder should have been used as a supplemental communication strategy during a scandal.

Crisis communication on social media best practices. The list of social media best practices during the crisis management process created by Veil et al. (2011) includes a lot of pre-crisis steps. Baylor's pre-crisis management plan cannot be evaluated, because this study only did a textual analysis of the communication during the scandal. However, Veil et al. also provide best practices for an organization to keep in mind while it is communicating during a scandal, including: share accurate and honest information, share messages with credible sources, humanize the organization's voice on social media, use social media as an updating tool, provide direction for stakeholders and remember that 
social media is a tool, but the impact of the communication relies on the quality of the content shared. Lin et al. (2016) add the practice of policing a hashtag if you promote it.

In its communications, Baylor University could have done better by sharing honest information, using credible sources and using social media as an updating tool. Although the university never necessarily lied, Baylor was never forthcoming with all of the information it knew, which is why the scandal lasted so long. As more information emerged during the scandal, fans and critics alike had reason to attack the university online. Not being transparent from the beginning hurt Baylor, because as the scandal continued its brand reputation continued to be negatively impacted. Further, as more information about the scandal emerged university officials became less credible in the fans' eyes. Because Baylor relied so heavily on sharing messages from university officials throughout the scandal, it was not able to follow the best practice of sharing messages with credible sources, which again, negatively impacted its reputation. The negative impact on the university's brand image is evidenced in fan tweets and will be discussed during the analysis that answers the second research question.

Veil et al. also recommends that social media be used as an updating tool during a scandal. Although @Baylor would post updates, they were often pretty vague. Additionally, very few updates, except about the new athletic director and coaching hires, were shared by @BUFootball and @BaylorAthletics. This left fans without the information they wanted and led to fans demanding more from their university and athletic department. Demanding more from Baylor is 
demonstrated in some of the fan tweets that were analyzed, and is discussed later in the findings.

In its communications, Baylor humanized its social voice and provided direction to its fans and followers. In online communication it is easy for an organization to appear as a robot or corporate drone, which is why using a human social voice is so important. Baylor primarily used quotes, both in the text of tweets and in graphics, as a way to humanize its communication over the course of the scandal. Additionally, @Baylor provided direction to its followers by encouraging them to either join the pledge to stop sexual violence or to give input on the presidential search.

It is not known if Baylor monitored the hashtags it promoted, because the university was not engaging with the tweets analyzed in this study. However, it was evident, that for the most part, the hashtags the university was using either got away from them or were not the same hashtags that fans were using. For example, \#TruthDontLie, which was being used by the football program and coaching staff completely veered off in the hands of the fans and critics as a way to point out that sexual assault occurred and could not be swept under the rug. On the other hand, fans did not readily adopt the hashtags the university was promoting, at least not to discuss the scandal. For example, the university account often used \#Baylor, whereas fans would often just write Baylor without the hashtag. This was probably because fans were not using many hashtags in their tweets and were more likely to tag the @Baylor account rather than use it as a hashtag. 
Conclusion. Baylor University's three Twitter accounts primarily used the same two crisis communication strategies: reminder/bolstering and corrective action. The strategies of apology and Bruce and Tini's (2008) diversion were also used, but very sparingly. According to crisis communication and social media scholars, the way Baylor communicated during the scandal was not the best and likely aided in the scandal lasting longer, which in turn further damaged the university's reputation. Overall, Baylor's communication throughout the scandal left something to be desired, which gave fans the perfect opportunity to weigh in and use crisis communication strategies both on behalf of and against Baylor.

\section{Baylor Fans}

Fans' tweets were collected between January 31, 2016 and February 3, 2017 on selected days of the scandal timeline. The list of the dates tweets were selected from can be found in Appendix B. A textual analysis was conducted in order to answer the second research question:

$R Q$ 2: What crisis communication strategies did Baylor University fans use on Twitter as the football sexual assault scandal unfolded between 2016 and 2017?

The analysis of tweets revealed that fans used several crisis communication strategies, including: scapegoat/shift the blame, diversion as proposed by Brown and Billings (2013), attack the accuser, victimage, differentiation, bolstering/reminder and ingratiation. Analysis also revealed that there were two groups of fans, especially during the first six months of the scandal: those fans who defended the university and its efforts during the crisis and those who blamed the university and criticized its efforts to communicate and remedy the 
scandal. These two groups of fans used some of these communication strategies in different ways.

Scapegoat/Shift the blame. It is no surprise that fans frequently shifted the blame during the scandal between 2015 and 2017. In crises, especially those of a serious nature, stakeholders want to know whom to blame, and Baylor fans were no different. They used this strategy to place the blame for the scandal and the poor decisions, including communication decisions that occurred as the scandal was emerging onto different actors involved in the scandal. Over the course of the scandal timeline fans pointed fingers at a lot of people, including: Baylor University Board of Regents, Ken Starr, Art Briles, Waco Police and the public relations firm hired by Baylor.

Baylor University board of regents. Many fans, both those who defended Baylor and those who blamed Baylor focused the blame for the scandal on Baylor's Board of Regents (BOR). The fans that defended the university and the football program during the scandal believed that the board was simply using other people like Art Briles and lan McCaw as scapegoats to save themselves. The anger fans had toward the BOR became more apparent a few months into the scandal and continued through the next several months. On May 26, 2016, the day it was announced Art Briles was let go, @pressmyhardsix tweeted, “@kendalbriles please let your dad know that many of us in the Baylor family do not support the BOR decision. Thank you both for contributing[.]" Similarly, a few days later on May 30,2016, when it was announced that lan McCaw had stepped down, @blffl tweeted, “@bu_ad1 Thanks for all you[']ve 
done for BU. Class act all the way to the end. You deserved better but rest assured Baylor Nation appreciates u[.]" Both of these tweets illustrate the sympathy fans had for Briles and McCaw and the blame they placed on the board of regents for letting these two individuals go.

Anger toward the board of regents continued into the summer. @txbarbydoll expressed her anger toward the board in her June 15, 2016 tweet, "Every single BaYlor [sic] BOR member should be investigated !! Release the report or get rid of them @BaylorAlumAssoc @BUFootball @BaylorAthletics[.]” This fan was upset because the board was not being transparent about what they knew about the scandal and those involved. @txbarbydoll appeared to feel the board is responsible for the crisis, which is why she called for the individuals on the BOR to be investigated.

It was easy for fans to continue to blame Baylor's Board of Regents because they felt they were not being listened to. The fans continually called for answers, and when answers weren't given, they made their disappointment known. On June 15, 2016, @TXWayne made his disappointment known in his tweet, "Just provided the Baylor BoR a piece of my mind, I wonder if they are smart enough to use mail rules or just delete email manually? \#deaf" By using the \#deaf, @TXWayne was indicating his frustration with the BOR for not addressing individuals concerns and questions. This fan also implied that the board was not paying attention to what fans and alumni were saying to the extent that they likely deleted the messages sent by these individuals. Further, 
@TXWayne attacked the board's intelligence, which could have encouraged other fans to shift the blame to the board.

The blame placed on the BOR continued, even when Baylor made what fans saw as good hiring decisions. Most fans were very excited to welcome the new athletic director and football coach to the program and felt that it was a turning point for the school. On July 13, 2016 @BaylorNick quote tweeted a tweet about what a great hire Mack Rhoades was for Baylor and added, "Until there is a change in the @Baylor Board of Regents, it may not matter, sadly[.]" Again, this fan appeared to believe the true issue and the root of the scandal lies with the BOR and although Baylor was trying to move forward, he feared the board would continue to plague the university.

This sentiment is echoed over the course of the next few months, and is illustrated in @jonschr October 5, 2016 tweet, “@TXJoyce Would be perfectly OK with the entire BOR and every VP and higher position turning over. Baylor embarrasses me. Needs to stop.”@TXJoyce later responded, “@jonschr That would be nice but who knows." These fans echoed the idea that Baylor would not be able to completely move on from the scandal until it cleaned house of everyone in a position of power during the scandal. It is likely that fans were not consciously trying to use this crisis communication strategy in favor of the university, rather they were probably just tweeting their opinions. However, by shifting the blame onto the board and the individuals in power, fans could have been attempting to focus the blame on specific individuals rather than the university as a whole. 
Ken Starr. Some fans blamed Ken Starr for the scandal Baylor faced and for the lack of transparency as people asked for more information about what was in the Pepper Hamilton report. One fan, @keithsena, shared his frustration with Ken Starr through a popular meme. On February 7, 2016, he tweeted a photo of a dog sitting in a room that is on fire with a note that stated, "How Ken Starr is handling matters right now[.]" The image and message tweeted out by @keithsena implied that Ken Starr was doing nothing while Baylor was going down in flames.

Some fans also called for Starr's resignation instead of settling for a demotion. On May 26, 2016, @LittleByrdEee tweeted, "It's egregious that @YABOYKENNYSTARR still is affiliated with Baylor. Ken Starr should be held responsible and completely dismissed." A few days later, on May 30, 2016, @dakotajday echoed @LittleBryrdEee's opinion in his tweet, “@ShehanJeyarajah I personally think that Ken star [sic] should step down as chancellor. That[']s coming from a Baylor fan[.]" Both of these tweets illustrated the blame that many fans placed on Ken Starr. By placing the blame on a particular person within the university the fans could have helped diminish the blame placed on the university as a whole, especially the innocent students, faculty and staff.

Art Briles. Many fans supported Art Briles throughout the scandal, but there was also a camp of fans that blamed him for the scandal. In a manner similar to the Penn State scandal, fans seemed torn between supporting their university and their fired coach (Brown et al., 2015); however, as more 
information emerged, more fans faulted Art Briles and blamed him for the scandal. On May 26, 2016, @BaylorGonnaBU tweeted, “@Bear_Force they were left no choice. Briles knew and did nothing, he needs to be fired. That's what the independent report says." This fan acknowledged that Briles was guilty of misconduct, essentially blaming him for the scandal. Contrary to what many fans were tweeting at this time, this fan also acknowledged that firing him was the right move. The group of fans blaming Briles grew in February 2017 when information about Art Briles' text messages emerged.

Fans were enraged to learn how far Briles had gone to cover up the sexual assault allegations. On February 3, 2017, @DrakeHowe tweeted, "Baylor fan yes! Fan of the way art briles [sic] and company handle these cases? No! Out with the old and in with the new! Baylor is making changes!" @fan_Baylor, another fan, tweeted, "Thankful for truth and closure. I'm abhorred in what Briles and company allowed in their complacency. Good riddance." Later the same day, @FantasyPastor quote tweeted a tweet about Art Briles' misconduct and stated, "As a Baylor alum it's disgusting to read these reports, but glad it is coming out and hope the program/Art Briles will be held accountable[.]" All of these fans appeared to blame Art Briles and his staff for the scandal. By focusing the blame on these individuals, especially so far into the scandal timeline, these fans were hoping that Baylor could move on and be better.

Waco police department. On May 18, 2016, Outside the Lines released a report claiming that the Waco Police Department helped cover up sexual assault allegations against Baylor football players. This report gave fans the 
perfect opportunity to shift part of the blame for the scandal onto the local police department. That day, @ecjackson77 quote tweeted the @OTLonESPN tweet that announced these allegations, and responded to this information by stating, "It seems that the Waco police, along with Baylor, should be in hot water over all of this too." This fan did not shift the entirety of the blame onto the Waco Police Department. By shifting the blame to the police department, @ecjackson77 seemed to be attempting to illustrate that the university did not have complete control over the scandal, and therefore should not bare all of the responsibility. It is not known if @ecjackson77 was consciously trying to convince others that the university should not shoulder all of the responsibility for the scandal, but by shifting the blame to an organization outside of the university, he could have helped reduce the amount of blame placed on the university by fans.

Public relations firm. A part of the reason the Baylor sexual assault scandal remained in the public eye for so long was because of the communication decisions made by Baylor as information about the scandal became publicly available. On February 7, 2016, right before Super Bowl L @Baylor tweeted out a press release regarding the scandal. This, of course, did not go over well as people felt that Baylor was trying to bury news about the ongoing scandal. @GoBearsGo95 responded to the tweet with, “@CraigSmoak @Baylor whatever PR firm is guiding BU needs to be fired." This fan recognized that Baylor was likely advised to send the tweet out right before the Super Bowl by a public relations firm. By shifting the blame for this decision to the PR firm, it appeared this fan was trying to redirect the blame the university was getting onto 
its communication adviser. By doing so, this fan could have helped alleviate some of the blame others were placing on the university by identifying other actors that should bear some responsibility, particularly when it came to the lack of transparency during the scandal.

Most of the blame was concentrated on a specific person or group of people within the university rather than shifting blame outside of Baylor, which is similar to the results from Brown et al. (2015) study. In their study about the Penn State sex abuse scandal, Brown et al. (2015) found that fans sided with their coach who had been fired during the crisis, and in turn shifted the blame onto actors within the university. Although not all Baylor fans supported their coach, there were many who did and therefore shifted the blame elsewhere.

During Baylor's scandal, the Board of Regents took the biggest hit from fan backlash. Fans blamed the BOR for the scandal, the lack of transparency and victimizing individuals at Baylor like Art Briles and lan McCaw. Of course, the board of regents wasn't the only group blamed in the scandal. There were fans that blamed Ken Starr and Art Briles. There were also some fans that blamed the PR firm for the poor communication, which led to a more tarnished brand image for Baylor. Further, some fans placed blame on the Waco Police Department for the role they played in covering up the sexual assault allegations. Regardless of whom the fans chose to blame, it didn't lessen the gravity of the scandal. Some fans could be considered as pseudo-crisis communicators on behalf of the university, but their efforts were diminished because of the university's 
communication mistakes, other fans who were blaming the university and the critics who continually spoke against Baylor.

Diversion. Fans who defended Baylor throughout the scandal commonly employed Brown and Billings' (2013) crisis communication strategy of diversion. Fans predominately used this communication strategy in an attempt to shift the public's focus from the scandal at Baylor to similar issues at other schools. Fans used diversion as a way to specifically and broadly point fingers at universities across the nation.

On January 31, 2016, @AFBaylorBear specifically pointed fingers at another university when they tweeted, “@pinepaula In addition, Baylor has acknowledged these incidents and have tried to address them, while other universities (FSU) ignore them." Here, the fan diverts attention to Florida State University and the sexual assault scandal it faced when its quarterback Jameis Winston was accused of sexually assaulting a woman. Further, @AFBaylorBear claimed that unlike Baylor, FSU did not handle the complaints appropriately. By shifting the focus from Baylor to Florida State, this fan could have been trying to show that similar issues occur elsewhere and can be worse than what occurred at Baylor.

Additionally, @BBentleyy used this strategy on June 6, 2016 in their tweet, "Thanks Stanford kid for switching up the headlines from Baylor for a bit." In a similar manner as @AFBaylorBear, this fan was diverting attention to another scandal involving a swimmer at Stanford who was convicted of sexual assault. Unlike the previous example, @BBentleyy does not imply that the situation at 
Baylor was handled better; rather, this fan was addressing a scandal that gave Baylor some reprieve from media attention.

Another example of diversion being used by a fan comes from @theebears in a series of two tweets they sent out on June 15, 2016. The first said, "Sex offenses on U.S. college campuses - The Washington Post...TCU \#1 in the state for rape of P5 universities," followed by, "The point is, it's a problem everywhere. It's sad and pathetic how some fans react so they can hope to win more games. Wash Post don't lie[.]" Here, @theebears was directly pointing fingers at what some may argue is Baylor's biggest rival, Texas Christian University (TCU). This tweet was this fan's way of proving that Baylor University's scandal is not bigger than what was going on at TCU, and used the credibility of the Washington Post to strengthen their argument. It is interesting that @theebears cited the Washington Post, because many other fans attacked the media over the course scandal. These examples show how fans used the strategy of diversion to focus on a specific scandal at another school, but there were also several fans that used this strategy to broadly call out all universities.

On May 26, 2016, @life_of_marge tweeted, "Sexual assault does not discriminate. It[']s not just a Baylor problem, it's not just an athlete problem." Here, this Baylor fan was acknowledging that yes, there was a problem at Baylor, but by no means was BU the only university that needed to address this issue. @life_of_marge seemed to be trying to garner some sympathy for the attention Baylor University had been receiving during the scandal while at the same time 
implying that individuals should look at their own schools and athletic departments and hold them accountable.

Similarly, @GannonDrake diverted attention to universities across the nation in his November 8, 2016 tweet, “@twoscoopsofpig so do you think title ix [sic] is working out? Baylor aside, many, many campuses are having issues with this[.]" @GannonDrake was stating that sexual assault was something that needed to be addressed universally across college campuses because many universities have a problem. Although he did not specifically address another school he was trying to divert attention to other programs. Both of these examples show how fans used diversion to broadly call out colleges around the nation.

The strategy of diversion, both specific and broad, is something that a university cannot employ without repercussions, but fans can use it in an attempt to share the negative media coverage with other universities that have similar issues (Brown and Billings, 2013). Therefore, it appears those fans that used this strategy to specifically divert attention to another university were stronger, compared to those who broadly diverted attention, because by giving a university to focus on, it gave both individuals and the media a specific school to investigate and potentially report on.

There were also some fans that were not defending Baylor and its actions during the scandal. These fans used this communication strategy in a couple different ways. First, these fans would partially divert attention to other universities but would return the attention to Baylor, because regardless of where 
else it happened, the way Baylor handled the situation was not right.

@1philipspencer's tweet on January 31, 2016 demonstrates this when he said, “@DougCofer @REV_93@OurDailyBears It is happening at other places, but this is OUR school. We wear "BU" so we must hold \#Baylor accountable." Although he acknowledged that sexual assault happens everywhere, @1philipspencer did not want fans to just let the problem at Baylor slide through the cracks. Instead, his tweet implied that everyone should hold his or her university accountable for handling this universal problem.

The second way these fans, who did not support or defend Baylor during the scandal, diverted attention was to previous Baylor scandals and actions, which is unique to this study. On May 26, 2016, @sctvi tweeted, "Have to say, though, l'd think Baylor would have been a bit more prudent in managing the athletic department after the scandal in 2003." Here, @sctvi was referring to when a Baylor basketball player was murdered by a teammate and the coach tried to cover up that he was violating NCAA rules by financially supporting the murdered player. This fan was shaming Baylor to an extent for not having more control over the athletic department, which in turn could have prevented this scandal.

Similarly, @ryanpatrick177 brought up the previous scandal in his June 1, 2016 tweet, "I remember dark days at Baylor in '03 when a basketball player killed a teammate. That was horrible but this feels different - so systemic." In this case, @ryanpatrick177 was stating that although the scandal from over ten years ago was bad, the current scandal is worse because it is a problem that the entire 
university failed to address correctly, rather than just the athletic department or basketball program. In this sense, this fan was also pointing out that the sexual assault scandal was a university-wide problem, not just an athletic department problem. By bringing up a previous scandal, these fans were reminding others about the mistakes individuals at Baylor made in the past, which can negatively impact the perception people have of the university. This negative perception could have further harmed the brand image that the university was trying to salvage during the scandal.

@TarkerPadlock associated Baylor with a public figure that many people have a negative view of in his July 13, 2016 tweet, "Anybody else find it EXTREMELY ironic that Baylor gave Bill Cosby an honorary degree?" A photo of Bill Cosby in a Baylor shirt attached accompanied the tweet. Here, the Baylor fan was diverting attention to a past action taken by Baylor and implied that the university rewards individuals who sexually assault women. Associating BU with Bill Cosby did not help its brand image because of the perception individuals have of him. The use of diversion in these instances did not divert attention away from the university, but rather onto previous scandals and actions of the university.

This use of diversion to previous crises and actions taken by the university currently facing a scandal has not appeared in any other study to date. It is not a strategy that would be used to enhance the program's reputation, and would never be used by the university, as it would bring even more negative attention to that school. If fans had more widely adopted the use of this strategy of diversion, 
they could have seriously altered the brand image of the university and made it more challenging for the school to recover.

Attack the accuser. There were many actors that fans attacked during Baylor's sexual assault scandal. The actors that accused Baylor of wrongdoing include Outside the Lines and ESPN, the media source that initially broke the story about Baylor's sexual assault scandal; Patty Crawford, Baylor's former Title IX coordinator who claimed Baylor tried to silence her; and the victims who reported being sexually assaulted. Similar to Brown and Billings (2013) study of the University of Miami scandal, Baylor fans took to Twitter to attack these accusers, especially ESPN and Outside the Lines. Employing this strategy allowed fans to question the credibility and character of the accusers, which in turn could have led their followers to question if what was being reported in regards to the scandal was true.

Outside the Lines and ESPN. Fans attacked ESPN most frequently and accused them of being biased and unethical in its reporting. On May 18, 2016, @ftblbob5 tweeted, “@ESPN_Big12 Waco police released a statement calling your piece sensationalism." This fan was suggesting that ESPN was not doing its due diligence as a media source by sharing an inaccurate story about the scandal. Later in the day, he sent another tweet stating, “@jmcelhoneiii @ESPN_Big12 So there's no chance that ESPN is trying to pump up their ratings through innuendo?;)," which insinuated that, to ESPN, ratings were more important than reporting the truth. A similar sentiment was shared by @TristanLMaynard in their October 19, 2016 tweet, "Being a Cowboys fan and a 
Baylor student, I have become real fed up with ESPN's negative media designed for attention and ratings." Calling ESPN's motives into question also raised the question of how credible its reports about the scandal were. Many fans believed ESPN was unfair and inaccurate in its reporting of the scandal, especially because ESPN owns the Longhorn Network (LHN), which is the sports channel for the University of Texas, one of Baylor's biggest rivals.

@theebears commented on ESPN's motives in relation to Baylor and the University of Texas rivalry in his June 15, 2016 tweet, "Anyone noticed that Fox Sports isn't quite as outraged at \#BAYLOR as espn [sic] is? Any thoughts as to why? Doesn't ESPN own the LHN? :). Mmmk[.]" Again, this fan was questioning ESPN's motives by implying that it only ran and held onto the story for so long for revenue purposes. Further, by pointing out that, in his opinion, ESPN held onto the story longer than other sports media, @theebears is questioning the biases, independence and credibility of ESPN. Fans likely used the idea that ESPN and its show Outside the Lines was fabricating or extenuating the truth about the scandal as a way to discredit the extent of the harm done by the scandal Baylor faced.

Other fans strayed away from the rival media attack method and focused on what they believed was the bigger story. On October 5, 2016, @jonschr quote tweeted a tweet about how Outside the Line's coverage of the Baylor scandal was exemplary. Disagreeing with this sentiment, @jonschr said, "Oh, come on. It was malpractice. They were right, in general, but missed the larger story. This was not about football." This fan, along with many others, argued that ESPN 
focused its coverage on the football program, but the problem at Baylor was never just an issue within the athletic department. By only focusing on the football team, fans appeared to believe that ESPN missed the story, and in that sense was not reporting ethically. Additionally, fans felt the media was targeting their team in an effort to either boost ratings or to severely harm the program, because they were only reporting on sexual assaults that were connected to the football program. The idea of harming the program is discussed more under the strategy of victimage.

Patty Crawford. On October 5, 2016, Patty Crawford went on CBS This Morning and claimed that Baylor tried to silence her. When other details emerged, fans were enraged and began pinning the blame for the scandal on her. @jonschr quote tweeted a tweet about Patty Crawford's interview, where she claimed that Baylor's brand was more important to university officials than properly handling sexual assault claims. Disagreeing with Crawford's argument, he tweeted, "BTW, you realize that 'protecting the brand' implies 'kicking out any accused student immediately.' That's the thing happening now." By attacking Crawford's argument, @jonschr was questioning her credibility in what appeared to be an attempt to weaken her argument against Baylor.

It was not challenging for fans to question Patty Crawford once more information emerged. On October 5, 2016, @ayvelascoo attacked Crawford in her tweet, "Patty Crawford cares so much about the students and their safety that she's [sic] tries to extort 2mil from Baylor and movie/book rights[.]" This fan was questioning Crawford's claims against Baylor and how much she truly cared 
about the students given she tried to get money from Baylor in addition to book and movie rights for her story (Lavigne and Schlabach, 2016). By positing these questions, @ayvelascoo was weakening Crawford's credibility and attacking her character. Attacking Crawford's character and credibility helped to weaken her argument against Baylor.

Victims. There were very few fans that attacked the victims, but nonetheless, some fans stood by the football players and administration at Baylor by attacking the credibility of the victims. Interestingly, at the beginning of the scandal the victims were not attacked, but as the scandal wore on and more information came out, fans began speaking out against the victims.

On November 8, 2016, @twoscoopsofpig attacked the victims by pointing out the flaws in their complaints about not being adequately helped after they were assaulted. In a quote tweet, @twoscoopsofpig commented on a tweet sent by another Baylor fan that placed blame on the head of the Baylor Police Department for not handling the sexual assault allegations correctly. @twoschoopsofpig stated, "Who says you can only report to one authority? Go elsewhere if you aren't being heard. WPD, the Sheriff, Constables, State Troopers..." Instead of siding with the other Baylor fan and placing the blame on the police for mishandling the allegations, this fan blamed the victims for not reporting their assault to more than one person or agency.

A couple months later on January 27,2017 , it was announced that a lawsuit was filed against Baylor University, which alleged that there were fifty-two rapes perpetrated by thirty-one football players in four years. Baylor fan, 
@_UrSoREPLACED tweeted, “There's such a gray area between what's actually rape and what's not. Most of them Baylor cases are girls regretting their actions." This fan attacked the victims by doubting their stories and claiming that they only came forward because they regretted having sex, not because they were raped. By attacking the victims, these fans were showing that they believed the players, administration and police did nothing wrong, at least not to the extent that was being reported. Additionally, these fans were opening the door for other individuals, fans and rivals alike, to question if the victims were telling the truth.

Overall, the strategy of attack the accuser was used as a way to defend the university throughout the scandal. This strategy was a good way for fans to try to distance Baylor from the scandal and to shift the attention elsewhere; however, the trade-off is that it could be detrimental to the accuser if it is widely believed and adopted as a crisis communication strategy. For example, it could have lead to individuals doubting the media and truth in journalism. In this case, it could have also lead to individuals blaming the victims who were assaulted rather than those who perpetuated and allowed the assaults to continue.

Victimage. Fans used the strategy of victimage as the scandal emerged to portray Baylor as a victim of its own naivety and of the media. When fans portrayed Baylor as a victim, it was not in regard to the sexual assaults that occurred; rather it was about Baylor's lack of knowledge on how to communicate during the scandal. In fans' opinions, there were several communication errors made by Baylor. On July 13, 2016, @BuGrizz illustrated this sentiment in his tweet, “@davidubben@Ben_Fred @stltoday Baylor not a bad place folks, great 
facilities, well funded...but victim of its own naivete." Here, this fan alluded to the fact that Baylor did not know how to properly handle sexual assault allegations and the scandal. By stating that Baylor is a victim of its own naivete, @BuGrizz appeared to be aiming to gain sympathy of the university.

Similarly, @LisaMarie noted that if Baylor had made better communication and personnel decisions, then the scandal would not have been as big of a deal. On September 10, 2016, she tweeted, “@brandyisme the story wouldn't have been this big had the $\mathrm{PH}$ report been kept internal \& Briles not fired. If Baylor had just made [the report] public[.]" This tweet implied that if Baylor had just been transparent about the scandal and what the administration knew, then the university and its personnel, like Art Briles, would have been better off and the story would have left the media's grasp sooner. Again, @LisaMarie implied that Baylor was a victim of its own mistakes, such as not being transparent.

Other fans positioned Baylor as a victim of the media. Fans posited that the media were treating Baylor unfairly during the scandal and in essence were trying to harm the university and its football program. On January 31, 2016, @AFBaylorBear, in reference to an article ESPN shared about the Outside the Lines report, tweeted, “@pinepaula Sounds like a hit piece to me. Baylor has not been silent. The suspects have all been expelled." This fan implied that ESPN was trying to take Baylor down by publishing an inaccurate article. By using the phrase "hit piece" @AFBaylorBear was suggesting that Baylor was a victim of a media organization that was purposely trying to harm it. 
Fans also claimed Baylor was a victim because the media focused its coverage on Baylor and not on the other universities that also faced similar issues. On January 31, 2016, @REV_93 tweeted, “@OurDailyBears I get it but ESPN shouldn't be acting like we are the only school." Here, @REV_93 portrays Baylor as a victim of the media because of ESPN's lack of coverage of similar issues at other universities. A few months later, @GannonDrake echoes this sentiment as well in his May 26, 2016, tweet, "People are absolute morons. I[']m so sick of media bombarding $[B]$ aylor as if $[B]$ aylor is the lone suspect..." In these tweet, it's assumed that these fans were trying to garner sympathy for Baylor while simultaneously vaguely diverting attention to other universities that have similar problems. They were also attacking the media by implying they were unnecessarily solely focusing on Baylor instead of reporting on all programs where there were incidents of sexual assault.

Victimage is typically used by an organization in an attempt to offset some of the anger associated with the crisis by evoking sympathy toward the organization. It is presumed that fans were trying to garner sympathy for the university by portraying Baylor as a victim. Tweets were used in an attempt to show that Baylor did not know better or that the university was a victim of unethical media coverage. Although the university should have been blamed, fans also wanted people to have some sympathy for the university because of the amateur mistakes made by employees at Baylor and the unfair media coverage. 
Differentiation. Fans primarily used differentiation as a crisis communication strategy to differentiate between terms. This strategy was not employed frequently, but was used to remind individuals that terminology matters. For example, on January 31, 2016, @baylor_logan tweeted, “@UT_HookEm @Baylor this is an insane allegation. [W]hat ever happened to innocent until proven guilty? And player never played a snap[.]" Here, @baylor_logan was calling out a critic for jumping the gun by accusing Baylor of being guilty when many of the wrongdoings reported by OTL were merely allegations. By differentiating between allegations and convictions, @baylor_logan was trying to place Baylor in a more favorable light. Similarly, @koehn_stephen tried to make the scandal seem less offensive when he differentiated between an allegation and conviction in his June 6, 2016 tweet, “@notthefakeSTU @WWMcClyde false. [S]hould not be punished for ALLEGATIONS. Show me where multiple convictions were made. Then talk justice."

$@$ Cooper1440 also used differentiation, but instead of focusing on an allegation compared to a conviction, he focused on the offensive act itself. On January 27, 2017, @Cooper1440 tweeted, “@SicEmSports @dallasnews @smervosh Total BS. Possibly assault allegations but not rape!" Here, the Baylor fan could have been trying to lessen the perception of violence associated with the scandal by differentiating between rape and assault. Although both acts are offensive, assault, to many, seems less offensive than rape. 
Bolstering/Reminder. Similar to the university, the fans that supported and defended the university during the scandal also used bolstering/reminder to focus on the good characteristics and actions of Baylor. On January 31, 2016, the day the Outside The Lines' (OTL) investigation into Baylor aired, @baylor_logan tweeted, “@RedRdr @keffjennedy @OTLonESPN lol you're judging an entire school off once inciden[t]. Everyone is blowing up this story because our success." In this tweet, @baylor_logan was suggesting that the only reason the media and critics have covered this scandal was because Baylor had a successful football program, and by focusing on the successes, this fan was using bolstering. This tweet also provides an example of multiple communication strategies being used in one tweet. By saying there was only one incident of sexual assault, this Baylor fan was minimizing how big the scandal was at that point. Additionally, this tweet attacks the media by calling into question its credibility. @baylor_logan appeared to think that the only reason the assaults at Baylor were reported on was because of the successful football program.

Similarly, @koehn_stephen used bolstering/reminder in his June 6, 2016 tweet, “@WWMcClyde blame who you want. End of day: 1 conviction in 8 years....Back to back Big12 champs...Can't take rings away[.]" Here, @koehn_stephen reminded his followers and @WWMcClyde that Baylor had a very successful football program and the ongoing scandal does not take that away. He stated that @WWMcClyde could blame who he wants, but implied that his blame was misplaced because of the quality of the football program. By focusing on the good aspects of the program, @koehn_stephen could have 
positively impacted Baylor's brand image during the scandal. Similar to @baylor_logan's tweet, this tweet also provides an example of the strategy minimization being used. @koehn_stephen states that there was only one conviction in eight years; however, Outside the Lines initially reported that Tevin Elliot and Sam Ukwuachu were both convicted of sexual assault (Lavigne, 2016). The strategy of minimization was rarely used throughout the course of the scandal. Using this strategy was bold in a scandal involving sexual assault because by minimizing the harm done, it could have offended individuals.

On July 13, 2016, the day it was announced that Mack Rhoades would be Baylor's new athletic director, @bufree99 tweeted, “@GabeDeArmond compare all sports and facilities Baylor has to look more attractive. Football was a top 10 team and still could be." When it was announced that Mack Rhoades would leave the University of Missouri to go to Baylor fans and critics alike had a lot to say. Many were surprised that Rhoades would want to go to Baylor given the campus climate. Fans like @bufree99 quickly came to Rhoades defense by bolstering the image of Baylor Athletics. By reminding people that Baylor had excellent sports facilities and good teams, @bufree99 was focusing on all the good reasons Mack Rhoades would want to work there. He also shifted @GabeDeArmond and his followers' attention onto the good aspects of Baylor Athletics. By focusing on the good characteristics of Baylor and the athletics department, fans could have been attempting to shift the attention away from the negative emotions associated with the scandal and onto the positive characteristics of Baylor. 
Ingratiation. There were some fans that used the strategy of ingratiation during the scandal to remind fans what it means to be a Baylor Bear fan. On May 26, 2016, @actress329 tweeted, “No matter what, l'll always be proud to be a Baylor Bear[.]" This tweet was a personal statement to @actress329's loyalty to Baylor and reminded fans that even through the tough times there were still reasons to be proud of identifying as a Baylor Bear. Similarly, on June 15, 2016, @VirtuouslySweet tweeted, "Come [rain] come [shine] a Baylor [Bear] I'll always be..." In her tweet, @VirtuouslySweet used emojis to express her fandom and loyalty to Baylor. She also reminded others that storms might come, but there's always something brighter to look forward to, and loyal fans would know that. @Fuentbu1 demonstrated the unity of being a Baylor fan in his June 1, 2016 tweet, “@Tap219 Baylor Nation is behind our Bears! \#SicEm \#WeAreMore” This fan was speaking to how Baylor Nation stands united behind the school and athletes and would continue to support them. These tweets helped to build goodwill between the university and its fans, which could have helped to offset some of the negative emotions associated with the scandal.

Conclusion. Baylor fans were very vocal on Twitter during the 2015-2017 sexual assault scandal. There were some fans that defended the university during the crisis and some fans that blamed the university for the scandal. The fans used seven crisis communication strategies throughout the scandal, including: scapegoat/shift the blame, diversion as proposed by Brown and Billings (2013), attack the accuser, victimage, differentiation, bolstering/reminder 
and ingratiation. Some fans used the strategy of diversion to focus attention on past scandals and actions that took place at Baylor, which is unique to this study. 


\section{Chapter 5: Discussion and Conclusion}

The purpose of this research was to look at how Baylor University and its fans acted as crisis communicators on Twitter during the $2015-2017$ sexual assault scandal. Per NCAA legislation, universities under investigation cannot publicly disclose information regarding the scandal until the investigation is complete; however, Baylor was never under NCAA investigation during the time frame studied (NCAA, 2016). The only restrictions placed on Baylor were on the individuals who were being sued, because they could not discuss the ongoing scandal during the legal process. Instead, Baylor most likely adhered to the university crisis management plan in place and took advice from the public relations firm it hired in order to determine what information to share and when to share it.

In order to answer the first research question, this study examined three Baylor University affiliated Twitter accounts to determine what crisis communication strategies were being used and how Baylor's communication compared to scholars crisis management recommendations. Analysis revealed that:

- @Baylor primarily used the communication strategies of corrective action and reminder/bolstering, and it was the only account to use the strategy of apology, although only once.

- @BUFootball used both reminder/bolstering the most frequently as a way to focus on the good things about the program, especially the community service aspect. They also employed the strategy of corrective action to share ways in which they were assuring the team and program would not tolerate sexual violence. 
- @BaylorAthletics used both corrective action and Bruce and Tini's (2008) strategy of diverting attention onto the innocent players who were affected by the scandal.

Overall, the analysis revealed that Baylor University's communication during the scandal could have been better. Throughout the scandal, the university did not employ all of the communication strategies nor follow the best practices outlined by scholars. Because of its missteps, Baylor lost control of the message surrounding the scandal, which allowed fans and critics to take over. One example of control lost was with Baylor's hashtag, \#TruthDontLie. Prior to the scandal, the athletics department and its employees were using this hashtag as a way to boast about the program's successes. On May 19, 2016, the day after OTL released more information about the Baylor scandal, Art Briles tweeted (Joseph, 2016):

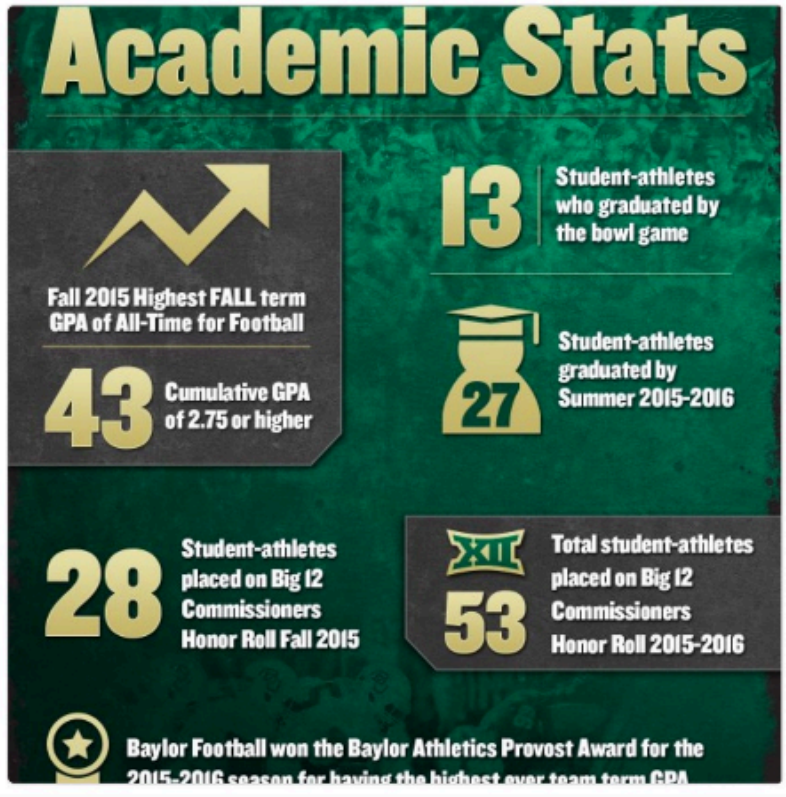


After Art Briles had tweeted this, many Twitter users took the opportunity to use \#TruthDontLie against Baylor and the football program by sharing the facts of the sexual assault scandal, such as the number of allegations. Although not the original intention for the hashtag, the conversation shifted and Baylor could not disown the new message. The best chance Baylor had to distance itself from this new hashtag was to discontinue its use and attempt to drown out the conversation with other content.

The university also would have benefitted from employing different communication strategies. Had the university been more transparent, apologized and offered some type of compensation to the victims, the scandal would have probably been out of the limelight sooner. Unfortunately for Baylor University, the scandal lasted longer and negatively impacted its brand image. This damage to its reputation will likely take the university years to repair.

The second research question focused on Baylor's fans and how they communicated on Twitter during the scandal. Analysis showed that two camps of fans emerged: those who defended the university and those who berated the university for its wrongdoings. Additionally, the analysis revealed that fans employed a wide range of crisis communication strategies, including: scapegoat/shift the blame, diversion (Brown and Billings, 2013), attack the accuser, victimage, differentiation, bolstering/reminder and ingratiation. The most interesting finding was the fact that some fans used the strategy of diversion to draw attention to previous scandals at Baylor. 
Unlike the university, fans can use some crisis communication strategies without repercussions, except maybe encountering some trolls or people who intentionally try to upset other people via interactions online. This means that fans can utilize crisis communication strategies that Baylor would never have used. For example, if the university employed Brown and Billings (2013) strategy of diverting attention to other schools, critics and fans would have probably critiqued the school for not focusing on fixing its problems and may have considered it petty to try to divert attention away from its wrongdoings.

Although fans can communicate on behalf of their school, it's important that the university knows when and how to engage with fans during a scandal. For example, if Baylor had liked or retweeted a tweet that was portraying Baylor as a victim of the media, individuals could have viewed this as a fan simply doing Baylor's dirty work, which would have negatively impacted Baylor's image. It surely would have led to several angry tweets being sent to @Baylor. It's important that a university considers what message it is sending when it engages with fan communication, especially during a crisis. The most important reason to engage with fans during a crisis is to provide clarifying information in an effort to be transparent and honest. It's equally important that if the university decides to engage with fans, especially those discussing the scandal, that the message is consistent with the organization's stance and values. It would not be appropriate for a school to retweet a fan as a way to share its message; rather the university should be responsible for crafting its own narrative. 
It's important that both universities and public relations firms understand how to effectively communicate during a scandal in order to minimize reputational damage. It's also important that they understand how to engage with fans, especially those communicating about the crisis. Hopefully this study provides some guidance and things to consider for universities and athletic departments as they are preparing or revising their crisis management guide. Although this thesis provides an example of the importance of utilizing appropriate crisis communication strategies on social media, this study was not without its limitations.

\section{Limitations and Future Research}

The limitations of this study emerged because of the decisions that were made in regards to the scandal studied, methods used and the data collection process. This study focused on Baylor University and how its fans communicated on Twitter during the 2015-2017 sexual assault scandal. During the research process for this study more information about the scandal emerged, which made it impossible to fully grasp the crisis communication strategies being used throughout the entirety of the scandal. Future crisis communication research should examine the Baylor sexual assault scandal as a whole. Additionally, this thesis only included 1.5 years of the Baylor scandal. Within that timeframe, communication from three of Baylor's Twitter accounts was gathered in its entirety, but fan communication was only gathered on key dates on the timeline. From these key dates only certain keyword search terms were used, which meant that some of the fan tweets about the scandal were missed and not 
included in this study. Future research studies should consider broadening the key terms and dates searched in order to obtain as many of the fan tweets as possible.

Additionally, this study assumed that fans do not knowingly employ crisis communication strategies in their social media communication, which is why only textual analysis was used in order to determine what crisis communication strategies were being employed. Future research should consider coupling this method with in-depth interviews; both with fans to understand what motivations and factors influenced a fan's decision to weigh in on the scandal, and with university employees in charge of communicating during a scandal in order to gain insight into the decision-making process they go through before publishing information.

Further, this study originally wanted to include both fan and @BUFootball followers in its data, because the followers of Baylor football likely weighed in on the conversation about the scandal. However, due to technical and time limitations, the followers were excluded from the sample. In the future, should a researcher have inside access to an organization, including the followers of a team into a crisis communication study could provide fruitful results. Additionally, this thesis only concerned itself with the crisis communication strategies taking place on one platform: Twitter. In the future, communication on other social platforms and a university's communication efforts as a whole should be studied. Further, by examining how social media fits into a university's pre-crisis management plan and how it is executed during the scandal may provide 
interesting results. Lastly, only studying one scandal could be considered a limitation, and in the future, researchers should compare how two organizations handle a similar scandal. 


\section{References}

Anderson, W. B. (2001). Saving the national pastime's image: Crisis management during the 1919 Black Sox scandal. Journalism History, 27(3), 17-38.

Baxter, P., \& Jack, S. (2008). Qualitative case study methodology: Study design and implementation for novice researchers. The Qualitative Report, 13(4), 544-559.

Benoit, W. L. (1997). Image repair discourse and crisis communication. Public relations review, 23(2), 177-186.

Berger, R. (2015). Now I see it, now I don't: Researcher's position and reflexivity in qualitative research. Qualitative Research, 15(2), 219-234.

Brown, N. A. (2014). The convergence of situational crisis communication theory and social media: Empirically testing the effectiveness of sports fan-enacted crisis communication (Doctoral dissertation, The University of Alabama Tuscaloosa).

Brown, N. A., \& Billings, A. C. (2013). Sports fans as crisis communicators on social media websites. Public Relations Review, 39(1), 74-81.

Brown, N. A., Brown, K. A., \& Billings, A. C. (2015). "May no act of ours bring shame": Fan-enacted crisis communication surrounding the Penn State sex abuse scandal. Communication \& Sport, 3(3), 288-311.

Bruce, T., and Tini, T. (2008). Unique crisis response strategies in sports public relations : Rugby league and the case for diversion. Public Relations Review, 34(2), 108-115.

Burroughs, B., \& Vogan, T. (2015). Media industries and sports scandals: Deadspin, Sports Illustrated, ESPN, and the Manti Te'o hoax. International Journal of Sports Communication, 8(1), 87-102.

Connelly, L. M. (2013). Grounded theory. MEDSURG, 22(2), 124 \& 127.

Coombs, W. T. (2014). Ongoing crisis communication: Planning, managing, and responding. Sage Publications. 
Coombs, W. T. (2007). Protecting organization reputations during a crisis: The development and application of situational crisis communication theory. Corporate Reputation Review, 10(3), 163-176.

Desilver, D. (2016). 5 facts about Twitter at age 10. Pew Research Center. Retrieved from: http://www. pewresearch.org/fact-tank/2016/03/18/5-factsabout-twitter-at-age-10/.

Dewey, C. (2016, June 16). 6 in 10 of you will share this link without reading it, a new, depressing study says. Washington Post. Retrieved from: https://www.washingtonpost.com/news/the-intersect/wp/2016/06/16/six-in-10of-you-will-share-this-link-without-reading-it-according-to-a-new-anddepressing-study/?utm_term=.6605b9fb55a3.

Favorito, J. (2012). Sports publicity: A practical approach. Routledge.

Gaudin, S. (2011). With 250M tweets per day, Twitter plans 'simplicity' strategy: CEO Dick Costolo discusses Twitter's growth, competing with Google+, Facebook. ComputerWorld. Retrieved from: http://www.computerworld.com/article/2499087/web-apps/with-250m-tweetsper-day--twitter-plans--simplicity--strategy.html.

Getting started with Twitter. (n.d.). Retrieved from: https://support.twitter.com/articles/215585.

Gibbs, C., \& Haynes, R. (2013). A phenomenological investigation into how Twitter has changed the nature of sport media relations. International Journal of Sport Communication, 6(4), 394-408.

Glaser, B. G., \& Strauss, A. L. (1967). The discovery of grounded theory: Strategies for qualitative research. Chicago: Aldine Publishing Company.

Grosbard, G. (2016). Baylor sexual assault scandal timeline: From football convictions to Title IX investigation. Sports Day. Retrieved from: http://sportsday.dallasnews.com/collegesports/baylorbears/2016/10/20/baylor-sexual-assault-scandal-timelinefootball-convictions-title-ix-investigation.

Joint statement of current law on religion in the public schools. (n.d.). American Civil Liberties Union. Retrieved from: https://www.aclu.org/other/jointstatement-current-law-religion-public-schools.

Jordan, T., \& Smith, D. (2013). Crisis communication in sport management: Research aides crisis response selection. KAHPERD Journal, 51(1), 26-34. 
Joseph, A. (2016, May 19). Art Briles tweets '\#TruthDontLie' amid mounting allegations at Baylor. USA Today. Retrieved from:

http://ftw.usatoday.com/2016/05/art-briles-tweet-truthdontlie-amid-allegationsbaylor-otl-college-football.

Kang, S. (2015). The mobile phone and professional sports: Fans' use of mobile content for loyalty, identification, and fandom. International Journal of Sport Communication, 8(4), 452-476.

Lavigne, P. (2016, February 2). Baylor faces accusations of ignoring sex assault victims. ESPN. Retrieved from:

http://www.espn.com/espn/otl/story/_/id/14675790/baylor-officials-accusedfailing-investigate-sexual-assaults-fülly-adequately-providing-support-allegedvictims.

Lavigne, P. \& Schlabach, M. (2016, October 5). Former Baylor title ix coordinator says school stood in her way. ESPN. Retrieved from: http://www.espn.com/college-football/story/_id/17720930/former-baylor-titleix-coordinator-patty-crawford-says-school-hindered-ability-do-job.

Lee, K. (2016). Why you should share to social media in the afternoon + more of the latest social media research. Buffer. Retrieved from: https://blog.bufferapp.com/new-social-media-research.

Lin, X., Spence, P. R., Sellnow, T. L., \& Lachlan, K. A. (2016). Crisis communication, learning and responding: Best practices in social media. Computers in Human Behavior, 65(1), 601-605.

Lordan, E. J. (2014). Sports and scandals: How leagues protect the integrity of their games. Santa Barbara: Praeger.

Matsa, K. E., and Lu, K. (2016). 10 facts about the changing digital news landscape. Pew Research Center. Retrieved from: http://www.pewresearch.org/fact-tank/2016/09/14/facts-about-the-changingdigital-news-landscape/.

McClung, S., Eveland, V., Sweeney, D., \& James, J.D. (2012). Role of the internet site in the promotion of sports teams and franchise brands. Journal of Promotion Management, 18(2), 169-188.

McKee, A. (2003). What is textual analysis?. Textual analysis: A beginner's guide (1-33). London: Sage.

Mission statement. (n.d.) Baylor University. Retrieved from: http://www.baylor.edu/about/index.php?id=88781. 
National Sexual Violence Resource Center. (2015). Info \& statistics for journalists: Statistics about sexual violence. Retrieved from:

http://www.nsvrc.org/sites/default/files/publications_nsvrc_factsheet_mediapacket_statistics-about-sexual-violence_0.pdf.

NCAA. (2016). Division I legislation 19.01.3: Public disclosure. Retrieved from: http://www.ncaapublications.com/productdownloads/D117.pdf.

Ott, L., \& Theunissen, P. (2015). Reputations at risk: Engagement during social media crises. Public Relations Review, 41(1), 97-102.

Pang, A., Cropp, F., \& Cameron, G. T. (2006). Corporate crisis planning: Tensions, issues, and contradictions. Journal of Communication Management, 10(4), 371-389.

Petrovici, A., \& Dobrescu, T. (2013). Public relations in sports. A case study. Gymnasium, 14(2), 121-127.

Ruihley, B. J., Pratt, A. N., \& Carpenter, T. (2016). The role of public relations in college athletics: Identifying roles, tasks, and importance of public relations. Journal of Applied Sport Management, 8(1), 52-74.

Saldaña, J. (2013). The coding manual for qualitative researchers. ( $2^{\text {nd }}$ ed.). London: Sage.

Sanderson, J., \& Hambrick, M. E. (2012). Covering the scandal in 140 characters: A case study of Twitter's role in coverage of the Penn State saga. International Journal of Sport Communication, 5(3), 384-402.

Scholl, J., \& Carlson, S. (2012). Professional sports teams on the web: A comparative study employing the information management perspective. European Sport Management Quarterly, 12(2), 137-160.

Seeger, M. W., Sellnow, T. L., \& Ulmer, R. R. (2003). Communication and organizational crisis. Greenwood Publishing Group.

Siah Ann Mei, J., Bansal, N., \& Pang, A. (2010). New media: a new medium in escalating crises?. Corporate Communications: An International Journal, 15(2), 143-155.

Stephens, K. K., \& Malone, P. C. (2009). If the organizations won't give us information...: The use of multiple new media for crisis technical translation and dialogue. Journal of Public Relations Research, 21(2), 229-239. 
Stoldt, G. C., Miller, K. K., Ayres, T. D., \& Comfort, P. G. (2000). Crisis management planning: A necessity for sport managers. International Journal of Sport Management, 1(4), 253-266.

Storm, R. K., \& Wagner, U. (2015). The Anatomy of the Sports Scandal: An Outline for a Theoretical Contextualization. International Journal of Sport Communication, 8(3).

Sutera, D. M. (2013). Sports fans 2.0: How fans are using social media to get closer to the game. Scarecrow Press.

Timeline: Baylor sexual assault controversy. (2017, February 16). Waco TribuneHerald. Retrieved from:

http://www.wacotrib.com/news/higher_education/timeline-baylor-sexualassault-controversy/article_abf21ab8-2267-51bf-84d8-6268f4222af0.html.

Veil, S. R., Buehner , T., \& Palenchar, M. J. (2011). A work-in-progress literature review: incorporating social media in risk and crisis communication. Journal of Contingencies and Crisis Management, 19(2), 110-122.

Wallace, L., Wilson, J., \& Miloch, K. (2011). Sporting Facebook: A content analysis of NCAA organizational sport pages and Big 12 conference athletic department pages. International Journal of Sport Communication, 4(4), 422444.

Walsh, J., \& Austin, G. P. (2013, September). Taking out the trash: An empirical investigation of strategic timing of news releases. Paper presented at New Directions in Text Analysis, London, 2013.

Wang, Y., \& Zhou, S. (2015). How do sports organizations use social media to build relationships? A content analysis of NBA Clubs' Twitter use. International Journal of Sport Communication, 8(2), 133-148.

Wann, D. L. (2006). The causes and consequences of sport team identification. In A. Raney and J. Bryant (Eds.). Handbook of sport and media (pp. 331352). Mahwah, NJ: LEA.

Wann, D. L., Melnick, M. J., Russell, G. W., \& Pease, D. G. (2001). Sport fans: The psychology and social impact of spectators. New York, NY: Routledge Press.

Wu, S., Tsai, C. D., \& Hung, C. (2012). Toward a team or player? How trust, vicarious achievement motive, and identification affect fan loyalty. Journal of Sport Management, 26(2), 177-191. 
York, A. (2017). 47 social media statistics to bookmark for 2017. Sprout Social. Retrieved from: www.sproutsocial.com/insights/social-media-statistics/. 
Table 1

\section{Appendix A}

Timeline of Scandal

Date

Sept. 3, 2015

Dec. 31, 2015

Jan. 31, 2016

Feb. 7, 2016

(Super Bowl L)

Feb. 8, 2016

\begin{tabular}{l}
\hline Feb. 12, 2016 \\
\hline March 6, 2016 \\
\hline March 30, 2016
\end{tabular}

\begin{tabular}{l} 
April 5, 2016 \\
\hline April 7, 2016
\end{tabular}

April 13, 2016

May 5, 2016

May 11, 2016

May 13, 2016

May 18, 2016

May 26, 2016

Sept. 2, 2015

(New Years Eve)

Scandal Event

Philadelphia law firm Pepper Hamilton hired to investigate Baylor University's handling of sexual violence.

University President Starr issued a statement that Boise State never told Baylor officials about Ukwauchu's violent history.

Baylor settles a lawsuit with a former student who was sexually assaulted by Ukwuachu, a former football player.

Outside the Lines released a video of three women claiming to have been sexually assaulted by football player Tevin Elliott.

Starr released a statement amidst criticism of how he was handling the scandal.

A vigil was held outside of Starr's home as activists called for better handling of sexual assaults.

Baylor vowed to hire more counselors and increase sexual assault training. Josh Anderson, a fraternity president, was for sexual assault. Jasmin Hernandez, a former student, filed a lawsuit against Baylor over its handling of sexual assault.

Baylor posted "Real men respect women" signs at practice facilities. Former defensive lineman Shawn Oakman accused of sexual assault.

Oakman was arrested after he was accused of sexual assault. Dallas Morning News released a report about how Baylor prioritizes football over the sexual assault victims. Josh Anderson was indicted for the alleged sexual assault. Baylor announced it had received the results from the Pepper Hamilton investigation.

Outside the Lines released a report accusing the Waco Police Department of covering up allegations against football players. A summary of the Pepper Hamilton Report was released to the public.

Coach Art Briles is fired, Starr is stripped of his title as university president and sanctions were placed on athletic director lan McCaw, who later resigned.

May 30, $2016 \quad$ Former Wake Forest coach Jim Grobe is hired to replace Briles.

(Memorial Day)
May 31, 2016

June 1, 2016

Football staffers Colin Shillinglaw and Tom Hill were fired.

Ken Starr resigns from his position as chancellor, but says he will still teach in the law school.

Several recruits ask to be released from the school.

Devin Chafin was released from the program for allegedly assaulting his girlfriend in 2014.

June 2, $2016 \quad$ Briles made his first statement after being fired and claimed that 


\begin{tabular}{|c|c|}
\hline & $\begin{array}{l}\text { Baylor never shared the results of the Pepper Hamilton Report with } \\
\text { him. }\end{array}$ \\
\hline June 3, 2016 & $\begin{array}{l}\text { A PR expert ends an interview Starr is doing after he said he might } \\
\text { have seen an email titled "I was raped at Baylor." }\end{array}$ \\
\hline June 6, 2016 & $\begin{array}{l}\text { Baylor announced it would not release the full Pepper Hamilton } \\
\text { Report. }\end{array}$ \\
\hline June 8,2016 & $\begin{array}{l}\text { Former student Dolores Lozano accused football staff of not taking } \\
\text { action against Chafin after she reported assault. }\end{array}$ \\
\hline June 9, 2016 & $\begin{array}{l}\text { Baylor elected to keep all of its assistant football coaches. } \\
\text { A Baylor student claimed to have been raped in } 2014 \text { by a football } \\
\text { player who is still on the team. }\end{array}$ \\
\hline June 13, 2016 & Baylor donors attempt to get Briles rehired. \\
\hline June 15, 2016 & $\begin{array}{l}\text { Three more women sued Baylor over its handlings of their sexual } \\
\text { assault cases. }\end{array}$ \\
\hline June 16, 2016 & Briles accused Baylor of wrongful termination. \\
\hline June 17,2016 & Baylor and Briles reached a settlement in his contract buyout. \\
\hline June 22, 2016 & $\begin{array}{l}\text { The Big } 12 \text { Conference asked Baylor to turn over all documents } \\
\text { related to sexual assaults on campus. }\end{array}$ \\
\hline June 28, 2016 & Three more women join the lawsuit against Baylor. \\
\hline June 29, 2016 & $\begin{array}{l}\text { Big } 12 \text { commissioner, Bob Bowlsby, told reporters that he is still } \\
\text { waiting on paperwork from Baylor. }\end{array}$ \\
\hline July 13,2016 & $\begin{array}{l}\text { Briles guaranteed he would coach again in } 2017 . \\
\text { Mack Rhoades is hired as the new athletic director. }\end{array}$ \\
\hline July 19,2016 & $\begin{array}{l}\text { Grobe and Bowlsby commented on the scandal during Big } 12 \text { Media } \\
\text { Days. }\end{array}$ \\
\hline July 20,2016 & Oakman was indicted on a sexual assault charge. \\
\hline July 23,2016 & Another woman joined the lawsuit against Baylor. \\
\hline July 25,2016 & $\begin{array}{l}\text { Brenda Tracy, sexual assault activist, visited Baylor and praised the } \\
\text { student athletes and coach for being attentive. }\end{array}$ \\
\hline July 28,2016 & $\begin{array}{l}\text { A fired staffer filed a petition for more information about why he was } \\
\text { fired. }\end{array}$ \\
\hline Aug. 2, 2016 & $\begin{array}{l}\text { Baylor changed its media policy, which restricts assistant coaches } \\
\text { from speaking with the media. }\end{array}$ \\
\hline Aug. 6, 2016 & $\begin{array}{l}\text { Baylor and Briles move to dismiss a Title IX lawsuit filed by a woman } \\
\text { raped by Elliot. }\end{array}$ \\
\hline Aug. 9, 2016 & $\begin{array}{l}\text { Briles attended Cowboys training camp and commented on the } \\
\text { scandal. }\end{array}$ \\
\hline Aug. 16, 2016 & Briles commented on the scandal at Houston Texans training camp. \\
\hline Aug. 19, 2016 & Starr leaves his position as a professor at the law school. \\
\hline Sept. 7, 2016 & $\begin{array}{l}\text { Patty Crawford, Baylor's Title IX coordinator, told athletic staffers that } \\
\text { sexual assault was a campus-wide issue. }\end{array}$ \\
\hline Sept. 10, 2016 & $\begin{array}{l}\text { Briles apologizes for his role in the scandal on ESPN College } \\
\text { GameDay. }\end{array}$ \\
\hline Sept. 16, 2016 & $\begin{array}{l}\text { Briles and Oakman attended Baylor's game against Rice. } \\
\text { Rice band made IX and star formations during the halftime show. }\end{array}$ \\
\hline Sept. 24, 2016 & $\begin{array}{l}\text { During an interview for the Texas Tribune Festival, Starr claimed } \\
\text { Baylor did not have a systemic problem, called for the full Pepper }\end{array}$ \\
\hline
\end{tabular}


Hamilton Report to be released, defended Briles and criticized the media for how they've handled the scandal.

\begin{tabular}{|c|c|}
\hline Sept. 30, 2016 & $\begin{array}{l}\text { Brenda Tracy, a sexual assault activist, wrote a post for Huffington } \\
\text { Post that painted the football program as guilty. }\end{array}$ \\
\hline Oct. 4, 2016 & Crawford resigns from position as Title IX coordinator. \\
\hline Oct. 5, 2016 & $\begin{array}{l}\text { Crawford went on CBS This Morning and claimed that Baylor tried to } \\
\text { silence her. }\end{array}$ \\
\hline Oct. 11, 2016 & $\begin{array}{l}\text { After a contradiction between stories the hashtag \#TRUTHDONTLIE } \\
\text { starts trending. }\end{array}$ \\
\hline Oct. 12,2016 & A pro-Briles RV was kicked off of Baylor's campus. \\
\hline Oct. 15, 2016 & $\begin{array}{l}\text { Baylor students used a float in the homecoming parade to protest } \\
\text { the administrations role in the scandal. }\end{array}$ \\
\hline Oct. 19,2016 & $\begin{array}{l}\text { U.S. Department of Education launched an investigation into how } \\
\text { Baylor handled sexual violence on campus. }\end{array}$ \\
\hline Oct. 28,2016 & $\begin{array}{l}\text { In interviews with The Wall Street Journal, the Board of Regents } \\
\text { stated that the extent of the Baylor scandal was bigger than } \\
\text { previously reported. }\end{array}$ \\
\hline Nov. 5, 2016 & $\begin{array}{l}\text { Baylor wore all black uniforms in game against TCU. A player } \\
\text { commented that it was in protest of Briles' firing. }\end{array}$ \\
\hline $\begin{array}{l}\text { Nov. 8, } 2016 \\
\text { (Election Day) }\end{array}$ & NCAA announced it will not "hammer down" on Baylor. \\
\hline Nov. 22, 2016 & $\begin{array}{l}\text { Baylor settles a lawsuit with two students who were gang raped by } \\
\text { football players. }\end{array}$ \\
\hline
\end{tabular}

Art Briles files a lawsuit alleging libel, slander and conspiracy against three Baylor regents and a senior administrator.

Dec. 11, 2016 The Board of Regents votes against another internal investigation into the university's handling of sexual assault claims.

Dec. 13, $2016 \quad$ Bears for Leadership Reform say the scandal could cost the school at least \$223 million.

Tom Hill, a former athletics employee, sues Pepper Hamilton law firm.

Jan. 12, $2017 \quad$ Baylor regents and administrators claim Briles made false statements in the lawsuit against them.

Jan. 16, 2017 According to Dallas Morning News, Baylor is seeing its second highest number of early applicants in school history.

Jan. 19, $2017 \quad$ Lyons, a former Title IX staff member at Baylor, tells ESPN that she faced discrimination and intimidation while investigating cases involving football players.

Jan. 27, $2017 \quad$ A graduate files a lawsuit against Baylor alleging a culture of sexual violence that included 52 rapes by 31 football players in four years. The lawsuit also alleges coaching staff would arrange for women to sleep with recruits on their visits.

Jan. 31, 2017 Shillinglaw, a former Baylor athletics staff member, files a lawsuit

(New Years Eve) alleging libel and slander against Baylor officials and Pepper Hamilton law firm.

Feb. 1, $2017 \quad$ Briles drops his lawsuit against Baylor regents and administrators. (Baylor's Birthday) 


\begin{tabular}{ll}
\hline Feb. 2, 2017 & $\begin{array}{l}\text { Information comes out showing that Briles and other football staffers } \\
\text { knew about infractions committed by players, including underage } \\
\text { drinking, sexual assault and indecent exposure, and actively covered } \\
\text { it up. }\end{array}$ \\
\hline Feb. 3, 2017 & $\begin{array}{l}\text { The Big 12 Conference board votes to withhold 25 percent of future } \\
\text { revenue payments from Baylor until the school proves it is following } \\
\text { conference bylaws and aspects of Title IX. }\end{array}$ \\
\hline
\end{tabular}


Table 2

\section{Appendix B}

\begin{tabular}{|c|c|c|}
\hline Date & Scandal Event & $\begin{array}{l}\text { Keywords } \\
\text { Searched }\end{array}$ \\
\hline Jan. 31, 2016 & $\begin{array}{l}\text { Outside the Lines released a video of three women } \\
\text { claiming to have been sexually assaulted by football } \\
\text { player Tevin Elliott. }\end{array}$ & $\begin{array}{l}\text { Baylor } \\
\text { \#BaylorScandal }\end{array}$ \\
\hline $\begin{array}{l}\text { Feb. 7, } 2016 \\
\text { (Super Bowl } \\
\text { L) }\end{array}$ & $\begin{array}{l}\text { Starr released a statement amidst criticism of how he } \\
\text { was handling the scandal. }\end{array}$ & $\begin{array}{l}\text { Baylor } \\
\text { \#ItsOnUs }\end{array}$ \\
\hline Feb. 8, 2016 & $\begin{array}{l}\text { A vigil was held outside of Starr's home as activists } \\
\text { called for better handling of sexual assaults. }\end{array}$ & $\begin{array}{l}\text { Baylor } \\
\text { \#ItsOnUs }\end{array}$ \\
\hline May 13,2016 & $\begin{array}{l}\text { Baylor announced it had received the results from the } \\
\text { Pepper Hamilton investigation. }\end{array}$ & $\begin{array}{l}\text { Baylor + report } \\
\text { Pepper + report } \\
\text { Pepper Hamilton } \\
\text { \#TruthDontLie }\end{array}$ \\
\hline May 18,2016 & $\begin{array}{l}\text { Outside the Lines released a report accusing the } \\
\text { Waco Police Department of covering up allegations } \\
\text { against football players. }\end{array}$ & $\begin{array}{l}\text { Waco Police } \\
\text { Baylor + Waco } \\
\text { \#TruthDontLie }\end{array}$ \\
\hline May 26, 2016 & $\begin{array}{l}\text { A summary of the Pepper Hamilton Report was } \\
\text { released to the public. } \\
\text { Coach Art Briles is fired, Starr is stripped of his title as } \\
\text { university president and sanctions were placed on } \\
\text { athletic director lan McCaw, who later resigned. }\end{array}$ & $\begin{array}{l}\text { Baylor } \\
\text { \#ItsOnUs } \\
\text { \#TruthDontLie }\end{array}$ \\
\hline $\begin{array}{l}\text { May 30, } 2016 \\
\text { (Memorial } \\
\text { Day) }\end{array}$ & $\begin{array}{l}\text { Former Wake Forest coach Jim Grobe is hired to } \\
\text { replace Briles. }\end{array}$ & Baylor \\
\hline June 1, 2016 & $\begin{array}{l}\text { Several recruits ask to be released from the school. } \\
\text { Devin Chafin was released from the program for } \\
\text { allegedly assaulting his girlfriend in } 2014 \text {. }\end{array}$ & Baylor \\
\hline June 6, 2016 & $\begin{array}{l}\text { Baylor announced it would not release the full Pepper } \\
\text { Hamilton Report. }\end{array}$ & Baylor \\
\hline June 15, 2016 & $\begin{array}{l}\text { Three more women sued Baylor over its handlings of } \\
\text { their sexual assault cases. }\end{array}$ & Baylor \\
\hline July 13, 2016 & $\begin{array}{l}\text { Briles guaranteed he would coach again in } 2017 . \\
\text { Mack Rhoades is hired as the new athletic director. }\end{array}$ & Baylor \\
\hline $\begin{array}{l}\text { Sept. 10, } \\
2016\end{array}$ & $\begin{array}{l}\text { Briles apologizes for his role in the scandal on ESPN } \\
\text { College GameDay. }\end{array}$ & $\begin{array}{l}\text { Art Briles } \\
\text { Baylor }+ \text { IX }\end{array}$ \\
\hline $\begin{array}{l}\text { Sept. 16, } \\
2016\end{array}$ & $\begin{array}{l}\text { Briles and Oakman attended Baylor's game against } \\
\text { Rice. } \\
\text { Rice band made IX and star formations during the } \\
\text { halftime show. }\end{array}$ & $\begin{array}{l}\text { Briles } \\
\text { Baylor + IX } \\
\text { Rice + IX } \\
\text { Rice band }\end{array}$ \\
\hline Oct. 5, 2016 & $\begin{array}{l}\text { Crawford went on CBS This Morning and claimed that } \\
\text { Baylor tried to silence her. }\end{array}$ & $\begin{array}{l}\text { Baylor + Crawford } \\
\text { Baylor + IX }\end{array}$ \\
\hline
\end{tabular}




\begin{tabular}{|c|c|c|}
\hline Oct. 19, 2016 & $\begin{array}{l}\text { U.S. Department of Education launched an } \\
\text { investigation into how Baylor handled sexual violence } \\
\text { on campus. }\end{array}$ & $\begin{array}{l}\text { Baylor + IX } \\
\text { Baylor + } \\
\text { investigation } \\
\text { Baylor + fed }\end{array}$ \\
\hline Nov. 5, 2016 & $\begin{array}{l}\text { Baylor wore all black uniforms in game against TCU. } \\
\text { A player commented that it was in protest of Briles' } \\
\text { firing. }\end{array}$ & $\begin{array}{l}\text { Baylor + uniform } \\
\text { Baylor + Briles }\end{array}$ \\
\hline $\begin{array}{l}\text { Nov. 8, } 2016 \\
\text { (Election Day) }\end{array}$ & $\begin{array}{l}\text { NCAA announced it will not "hammer down" on } \\
\text { Baylor. }\end{array}$ & $\begin{array}{l}\text { Baylor + IX } \\
\text { Baylor + NCAA }\end{array}$ \\
\hline $\begin{array}{l}\text { Dec. 7-8, } \\
2016\end{array}$ & $\begin{array}{l}\text { Matt Rhule is introduced as the new football head } \\
\text { coach. } \\
\text { Art Briles files a lawsuit alleging libel, slander and } \\
\text { conspiracy against three Baylor regents and a senior } \\
\text { administrator. }\end{array}$ & $\begin{array}{l}\text { Baylor + Rhules } \\
\text { Coach Rhules } \\
\text { Baylor + Briles }\end{array}$ \\
\hline Jan. 27, 2017 & $\begin{array}{l}\text { A graduate files a lawsuit against Baylor alleging a } \\
\text { culture of sexual violence that included } 52 \text { rapes by } \\
31 \text { football players in four years. The lawsuit also } \\
\text { alleges coaching staff would arrange for women to } \\
\text { sleep with recruits on their visits. }\end{array}$ & $\begin{array}{l}\text { Baylor + rape } \\
\text { Baylor + lawsuit }\end{array}$ \\
\hline $\begin{array}{l}\text { Feb. 2-3, } \\
2017\end{array}$ & $\begin{array}{l}\text { Information comes out showing that Briles and other } \\
\text { football staffers knew about infractions committed by } \\
\text { players, including underage drinking, sexual assault } \\
\text { and indecent exposure, and actively covered it up. }\end{array}$ & $\begin{array}{l}\text { Baylor + Briles } \\
\text { Briles + text }\end{array}$ \\
\hline
\end{tabular}




\section{Appendix C}

Table 3

Codebook for Tweets

Crisis communication

strategy

Strategy classification

Attack the accuser

(Coombs, 2007; Benoit, Primary response

strategies- denial 1997)

crisis response

strategies

Definition

Example

Reducing

offensiveness

(Simple) denial

Primary response

Denying that

(Coombs, 2007; Benoit,

strategies- denial

anything wrong 1997)

crisis response

happened.

When the credibility

and character of the

accuser is

questioned.

Attacking the

media's

intentions

and

credibility.

strategies

Denial

\begin{tabular}{ll}
\hline Scapegoat/Shift the blame & Primary response \\
(Coombs, 2007; Benoit & strategies- denial \\
1997) & crisis response \\
& strategies \\
\cline { 2 - 2 } & Denial
\end{tabular}

An individual or another organization is blamed.

Denying that there's a sexual assault problem at Baylor.

Placing the blame on the Board of Regents or the media instead of on Art Briles.

\begin{tabular}{|c|c|c|c|}
\hline $\begin{array}{l}\text { Excuse } \\
\text { (Coombs, 2007) }\end{array}$ & $\begin{array}{l}\text { Primary response } \\
\text { strategies- } \\
\text { diminish crisis } \\
\text { response } \\
\text { strategies }\end{array}$ & $\begin{array}{l}\text { The organization } \\
\text { tries to minimize the } \\
\text { severity of the crisis } \\
\text { by denying the intent } \\
\text { to do harm, or by } \\
\text { saying they had no } \\
\text { control in what } \\
\text { happened. }\end{array}$ & $\begin{array}{l}\text { Baylor/fans } \\
\text { thought } \\
\text { sexual } \\
\text { assault } \\
\text { investigations } \\
\text { were being } \\
\text { handled } \\
\text { properly. } \\
\end{array}$ \\
\hline $\begin{array}{l}\text { Justification/Minimization } \\
\text { (Coombs, 2007; Benoit, } \\
\text { 1997) }\end{array}$ & $\begin{array}{l}\text { Primary response } \\
\text { strategies- } \\
\text { diminish crisis } \\
\text { response } \\
\text { strategies } \\
\text { Reducing } \\
\text { offensiveness }\end{array}$ & $\begin{array}{l}\text { Downplay the } \\
\text { seriousness of the } \\
\text { damage. }\end{array}$ & $\begin{array}{l}\text { Claim that } \\
\text { fewer } \\
\text { assaults } \\
\text { happened } \\
\text { than what's } \\
\text { being } \\
\text { reported. }\end{array}$ \\
\hline $\begin{array}{l}\text { Compensation (Coombs, } \\
2007 \text { ) }\end{array}$ & $\begin{array}{l}\text { Primary response } \\
\text { strategies- rebuild } \\
\text { crisis response } \\
\text { strategies }\end{array}$ & $\begin{array}{l}\text { Offer compensation } \\
\text { to the victims. }\end{array}$ & $\begin{array}{l}\text { Offer } \\
\text { additional } \\
\text { support } \\
\text { services and } \\
\text { resources to } \\
\text { the victims. }\end{array}$ \\
\hline Apology/Mortification & Primary response & Organization & ans \\
\hline
\end{tabular}




\begin{tabular}{|c|c|c|c|}
\hline $\begin{array}{l}\text { (Coombs, 2007; Benoit, } \\
\text { 1997) }\end{array}$ & $\begin{array}{l}\text { strategies- rebuild } \\
\text { crisis response } \\
\text { strategies } \\
\text { Mortification }\end{array}$ & $\begin{array}{l}\text { accepts full } \\
\text { responsibility and } \\
\text { asks for forgiveness. }\end{array}$ & apologize. \\
\hline $\begin{array}{l}\text { Ingratiation } \\
\text { (Coombs, 2007) }\end{array}$ & $\begin{array}{l}\text { Secondary } \\
\text { response } \\
\text { strategies- } \\
\text { bolstering crisis } \\
\text { response } \\
\text { strategies }\end{array}$ & $\begin{array}{l}\text { When the } \\
\text { stakeholders are } \\
\text { praised and/or } \\
\text { reminded about the } \\
\text { good work of the } \\
\text { organization. }\end{array}$ & $\begin{array}{l}\text { Praising the } \\
\text { fan-base and } \\
\text { returning } \\
\text { players for } \\
\text { being loyal. }\end{array}$ \\
\hline $\begin{array}{l}\text { Victimage } \\
\text { (Coombs, 2007) }\end{array}$ & $\begin{array}{l}\text { Secondary } \\
\text { response } \\
\text { strategies- } \\
\text { bolstering crisis } \\
\text { response } \\
\text { strategies }\end{array}$ & $\begin{array}{l}\text { The organization is } \\
\text { portrayed as a victim } \\
\text { too. }\end{array}$ & $\begin{array}{l}\text { The media is } \\
\text { being } \\
\text { unnecessarily } \\
\text { harsh on } \\
\text { Baylor. }\end{array}$ \\
\hline $\begin{array}{l}\text { Reminder/Bolstering } \\
\text { (Coombs, 2007; Benoit, } \\
\text { 1997) }\end{array}$ & $\begin{array}{l}\text { Secondary } \\
\text { response } \\
\text { strategies- } \\
\text { bolstering crisis } \\
\text { response } \\
\text { strategies } \\
\text { Reducing } \\
\text { offensiveness }\end{array}$ & $\begin{array}{l}\text { Focus is shifted to } \\
\text { the organization's } \\
\text { good characteristics } \\
\text { and actions. }\end{array}$ & $\begin{array}{l}\text { Baylor has a } \\
\text { strong history } \\
\text { and } \\
\text { commitment } \\
\text { to excellence. }\end{array}$ \\
\hline $\begin{array}{l}\text { Provocation } \\
\text { (Benoit, 1997) }\end{array}$ & $\begin{array}{l}\text { Evasion of } \\
\text { responsibility }\end{array}$ & $\begin{array}{l}\text { The bad thing } \\
\text { happened in } \\
\text { response to } \\
\text { something else that } \\
\text { happened. }\end{array}$ & $\begin{array}{l}\text { The scandal } \\
\text { happened } \\
\text { because Title } \\
\text { IX laws } \\
\text { changed. }\end{array}$ \\
\hline $\begin{array}{l}\text { Defeasibility } \\
\text { (Benoit, 1997) }\end{array}$ & $\begin{array}{l}\text { Evasion of } \\
\text { responsibility }\end{array}$ & $\begin{array}{l}\text { The crisis } \\
\text { happened, but the } \\
\text { organization lacked } \\
\text { control of enough } \\
\text { information to alter } \\
\text { the outcome. }\end{array}$ & $\begin{array}{l}\text { Baylor lacked } \\
\text { information } \\
\text { from Waco } \\
\text { PD, the Title } \\
\text { IX office or } \\
\text { the football } \\
\text { program. }\end{array}$ \\
\hline $\begin{array}{l}\text { Accident } \\
\text { (Benoit, 1997) }\end{array}$ & $\begin{array}{l}\text { Evasion of } \\
\text { responsibility }\end{array}$ & $\begin{array}{l}\text { The scandal wasn't } \\
\text { supposed to } \\
\text { happen. }\end{array}$ & \\
\hline $\begin{array}{l}\text { Good intentions } \\
\text { (Benoit, 1997) }\end{array}$ & $\begin{array}{l}\text { Evasion of } \\
\text { responsibility }\end{array}$ & $\begin{array}{l}\text { Looking back it was } \\
\text { a mistake, but we } \\
\text { meant well. }\end{array}$ & $\begin{array}{l}\text { How Baylor } \\
\text { handled it } \\
\text { was } \\
\text { incorrect, but } \\
\text { the leaders } \\
\text { thought they } \\
\text { were doing } \\
\text { what's best } \\
\text { for the school } \\
\text { and its }\end{array}$ \\
\hline
\end{tabular}




\begin{tabular}{|c|c|c|c|}
\hline & & & students \\
\hline $\begin{array}{l}\text { Differentiation } \\
\text { (Benoit, 1997) }\end{array}$ & $\begin{array}{l}\text { Reducing } \\
\text { offensiveness }\end{array}$ & $\begin{array}{l}\text { The offensive action } \\
\text { is compared to a } \\
\text { similar, but more } \\
\text { offensive action. }\end{array}$ & $\begin{array}{l}\text { Comparing } \\
\text { an allegation } \\
\text { to a guilty } \\
\text { verdict. }\end{array}$ \\
\hline $\begin{array}{l}\text { Transcendence } \\
\text { (Benoit, 1997) }\end{array}$ & $\begin{array}{l}\text { Reducing } \\
\text { offensiveness }\end{array}$ & $\begin{array}{l}\text { The offensive action } \\
\text { is placed into a more } \\
\text { favorable light by } \\
\text { comparing it to the } \\
\text { alternatives. }\end{array}$ & $\begin{array}{l}\text { Covering up } \\
\text { the assaults } \\
\text { had to } \\
\text { happen so } \\
\text { Baylor could } \\
\text { have a } \\
\text { winning } \\
\text { football } \\
\text { program. }\end{array}$ \\
\hline $\begin{array}{l}\text { Corrective action } \\
\text { (Benoit, 1997) }\end{array}$ & Corrective action & $\begin{array}{l}\text { There's a plan to } \\
\text { correct the problem } \\
\text { and/or avoid it in the } \\
\text { future. }\end{array}$ & $\begin{array}{l}\text { New staff, } \\
\text { policies and } \\
\text { procedures } \\
\text { are being put } \\
\text { into place. }\end{array}$ \\
\hline $\begin{array}{l}\text { Diversion- innocent actors } \\
\text { (Bruce \& Tini, 2008) }\end{array}$ & & $\begin{array}{l}\text { When attention is } \\
\text { shifted to the } \\
\text { organization } \\
\text { members and } \\
\text { audiences that are } \\
\text { negatively impacted. }\end{array}$ & $\begin{array}{l}\text { Discussing } \\
\text { how recruits } \\
\text { and innocent } \\
\text { football } \\
\text { players are } \\
\text { being } \\
\text { impacted by } \\
\text { the scandal. }\end{array}$ \\
\hline $\begin{array}{l}\text { Diversion- other schools } \\
\text { (Brown \& Billings, 2013) }\end{array}$ & & $\begin{array}{l}\text { When attention is } \\
\text { shifted to other } \\
\text { schools' scandals } \\
\text { and problems. }\end{array}$ & $\begin{array}{l}\text { Shifting } \\
\text { attention to } \\
\text { sexual } \\
\text { assault on } \\
\text { other } \\
\text { campuses. }\end{array}$ \\
\hline
\end{tabular}




\section{Appendix D}

Tweets sent by Baylor University, Baylor football and Baylor Athletic Department organized by Twitter account, crisis communication strategy and in the order they appear in the findings chapter.

\section{@Baylor}

Vague corrective action.

Baylor University @ Baylor - 12 Feb 2016

\#Baylor Regents approve action plan to prevent sexual violence on campus \&

improve services for those impacted: bit.ly/1XoqibE
A 8
เ7. 34
49

\section{Baylor University @Baylor · 5 Apr 2016}

\#BAYLOR NATION: Please join professors and students in pausing for a moment of prayer/reflection. \#SAAM \#ItsOnUsBU

\section{Pray that all of us will treat one another with} dignity and respect as beloved children of God. [Ephesians 5:1-2]

\section{Pray that each person within our community} will know peace, safety, and freedom from anxiety so that they can learn and grow toward their God-given potential. [John 14:27]

\section{Pray for the wisdom of our leaders as they} shape efforts to prevent interpersonal violence and care for survivors of sexual assault. [1 Timothy 2:1-2]

\section{Pray that each of us will look out for others,} choosing to act for the safety and protection of all. [Philippians 2:4-5]
4
ㄴำ 42
105 
Baylor University @Baylor + 23 Aug 2016

Since June, \#Baylor has completed/made significant progress on over $3 / 4$ of sexual assault response recommendations: bit.ly/2bg9Ax8

ค 3 ㄴำ11 24

\section{Specific corrective action.}

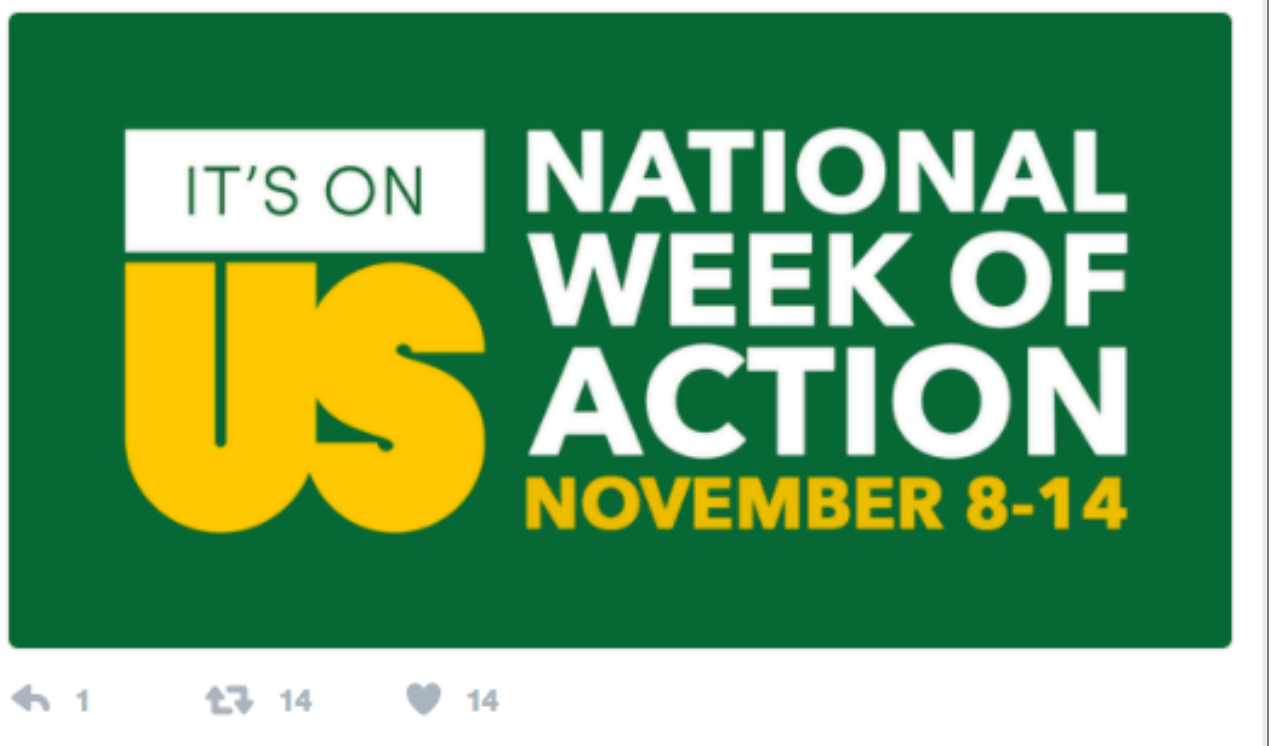

\section{Baylor University @Baylor · 29 Jun 2016}

The \#Baylor Counseling Center is reducing wait times, limiting fees \& eliminating session limits: bit.ly/295bqhG (5/5)

An Update from President Garland
$\begin{aligned} & \text { President David Garland updates the Baylor family on } \\ & \text { the University's efforts to move forward as an institution, } \\ & \text { and discusses the incoming class that were welcome... } \\ & \text { baylor.edu }\end{aligned}$
47.15




\section{Reminder/bolstering.}

A Baylor University @Baylor - 29 Jun 2016

\#Baylor is hiring additional counselors that will make our student-to-counselor

BAYLIOR ratio among the nation's best: bit.ly/295bqhG (4/5)
H 1
ㄴㄱ 3
24

\section{Baylor University @Baylor · 30 Dec 2016}

Thank you, Bears! Your love led to \#Baylor being named the nation's No. 1 university on Facebook \& No. 3 on Twitter! bit.ly/2ixTxLj

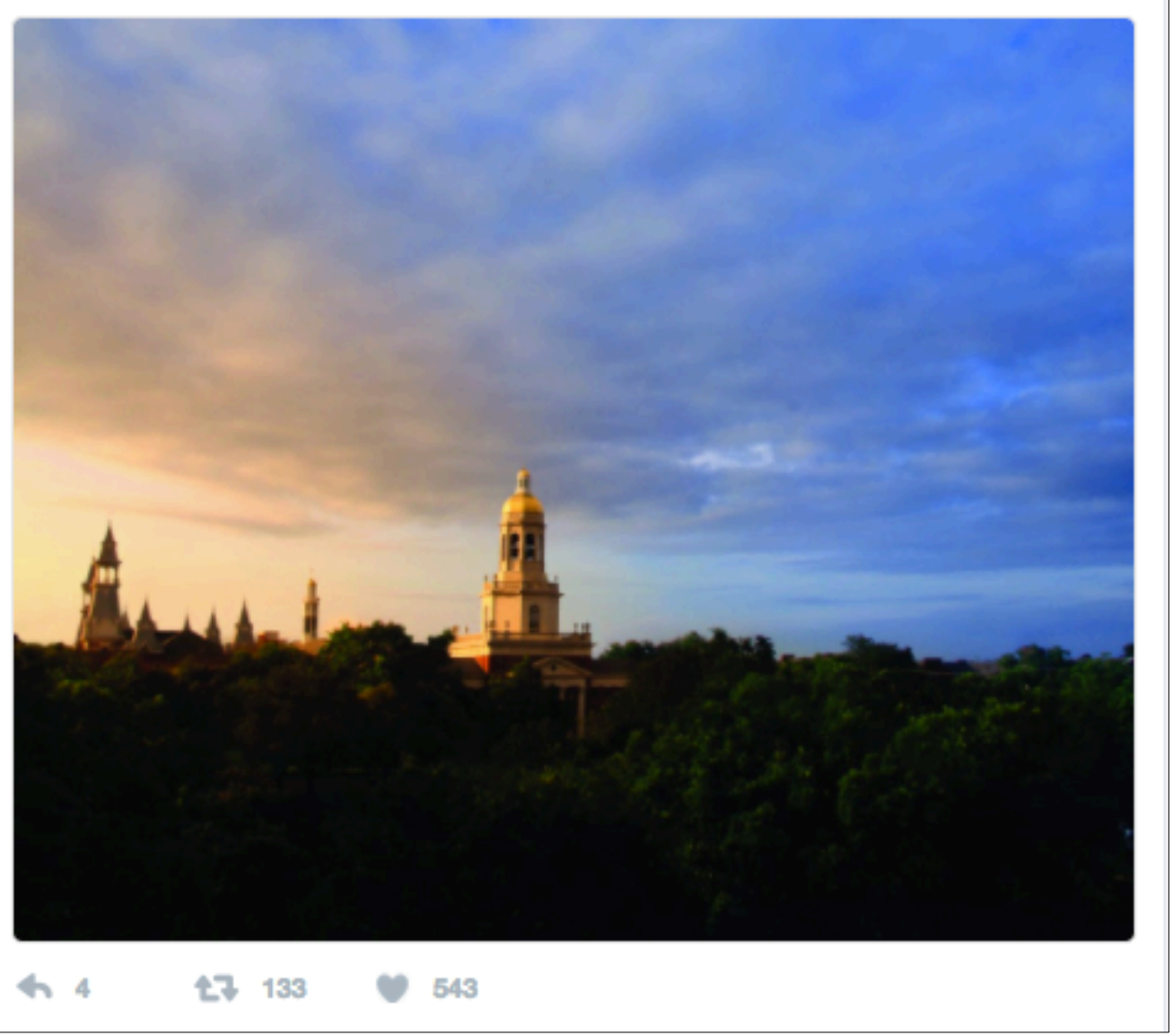


Baylor University $\diamond$ Baylor - 15 Nov 2016

This weekend, more than 2,000 students served the \#Waco community during \#Baylor's Steppin Out event: bit.ly/2fCFSRy \#BaylorServes

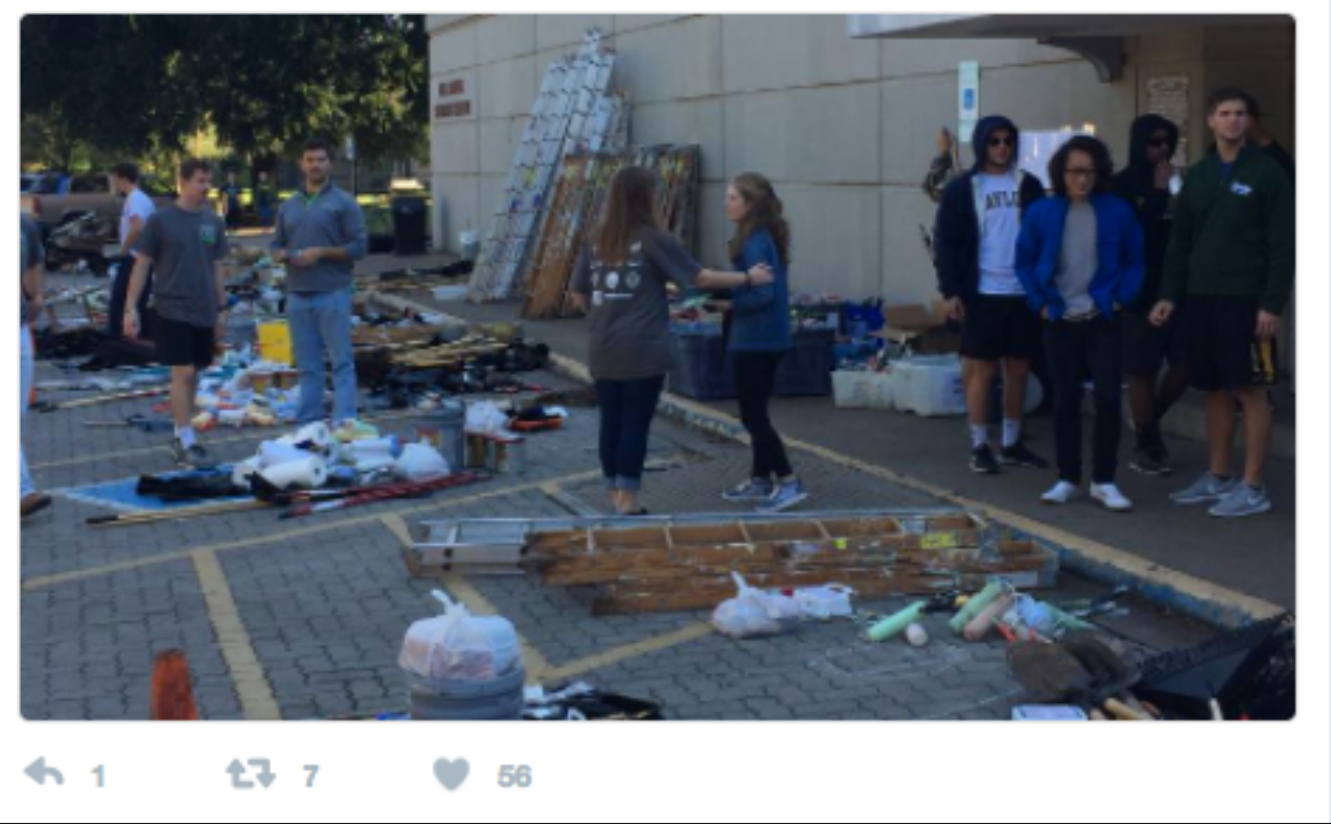

Baylor University @ Baylor · 4 Jun 2016

\#Baylor: "We are deeply sorry for the harm that survivors have endured."

Dear Baylor Nation,

We have entered a new season in the life of Baylor University. It is a season that calls for clarity, compassion and collective action as a Christian academic community and as a body of Baylor alumni that spans multiple generations, often within individual families. It is a season that calls for Baylor to stand together and speak as one voice, resolute in our shared commitment to student welfare and safety and to our institutional values.

I am honored and humbled that the Regents have asked me again to serve as Baylor's interim president. I also want to recognize that the work lying ahead must be undertaken by the hearts and hands of the many thousands of Baylor students, faculty and staff, alumni and friends for whom Baylor is a treasured institution. We are called to come together in prayerful reflection and honest action.

I echo the sentiments of our Board Chair Ron Murff, "We, as the governing Board of this University, offer our apologies to the many who sought help from the University. We are deeply sorry for the harm that survivors have endured."
h 3
ㄴ. 4
24 


\section{@BUFootball}

\section{Bolstering/reminder.}

Baylor Football @BUFootball ·26 Dec 2015

Hula hoop game is strong as players visit with terminally ill children.

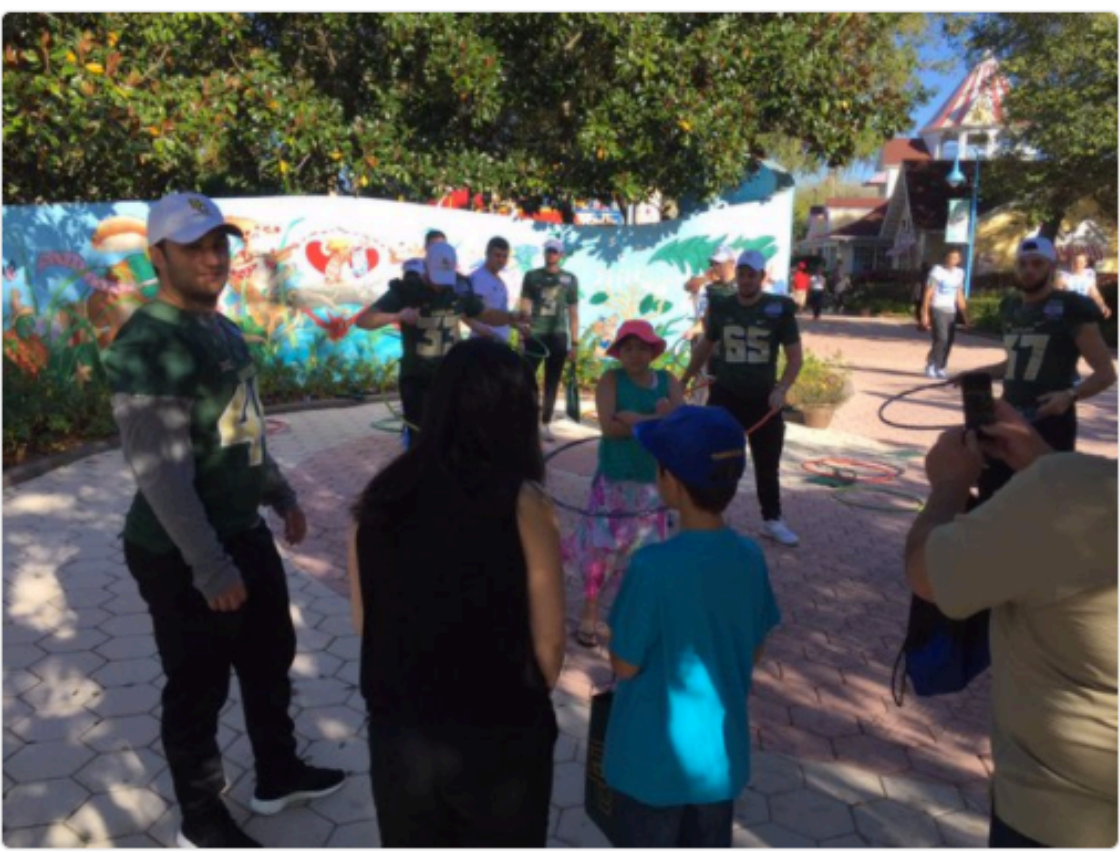
< 2
1215
64

Baylor Football @ @UFootball · 27 Apr 2016

Bears hard at work, giving back to the Waco community. \#SicEm

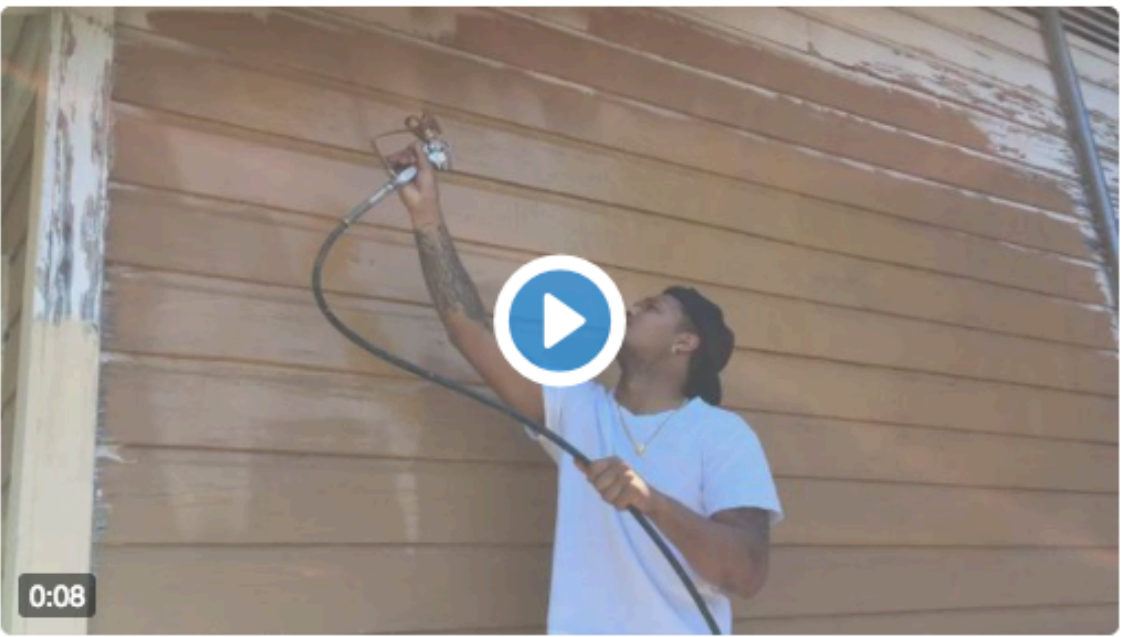
\& 3
ใ7 17
53 
Baylor Football» @BUFootball · Jan 16

This morning players joined with other Baylor students to honor the \#MLK

legacy by volunteering their time as part of \#MLKDayofService.

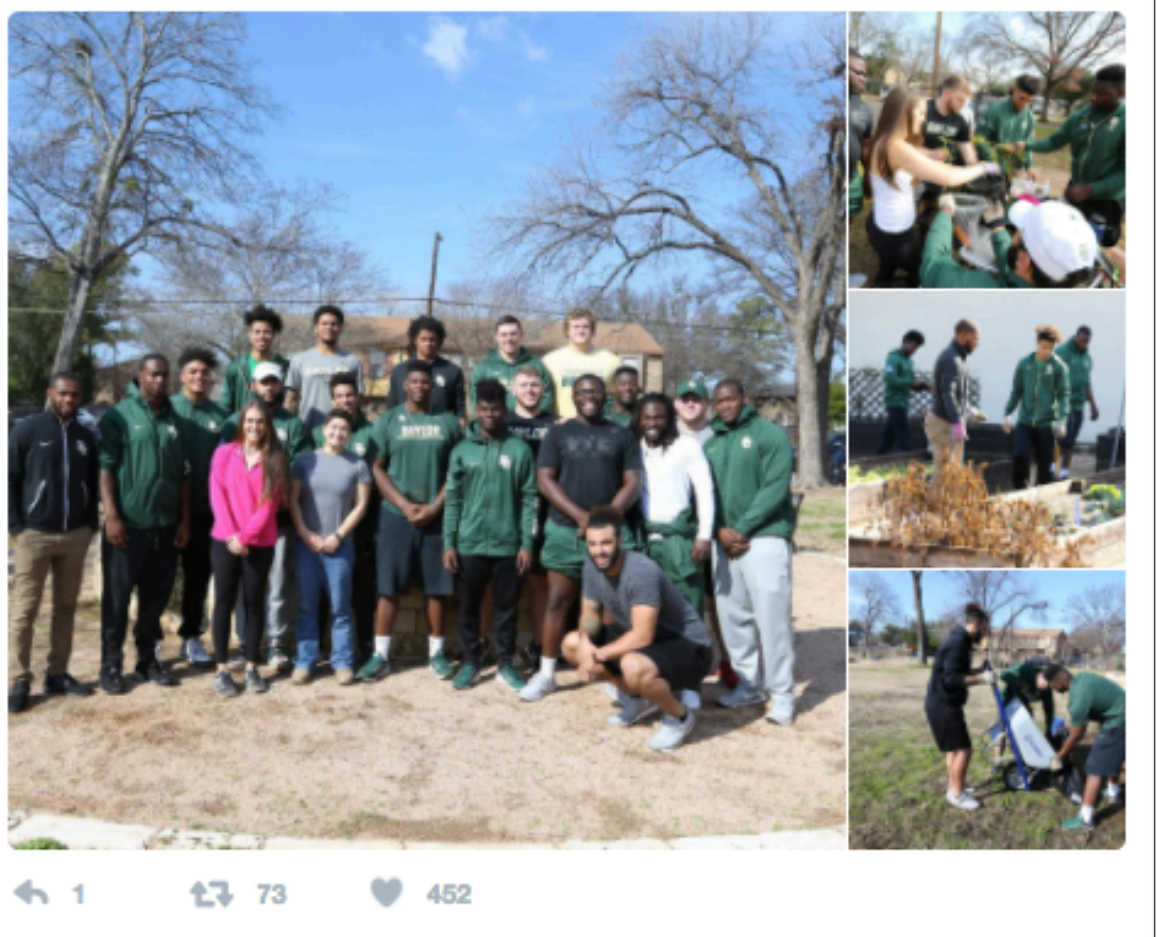

\section{Baylor Footballo @BUFootball · 7 Dec 2016}

"It's not often in life that you get off a plane in a new place, and say to yourself 'Oh, this feels like home.'" \#SicEm

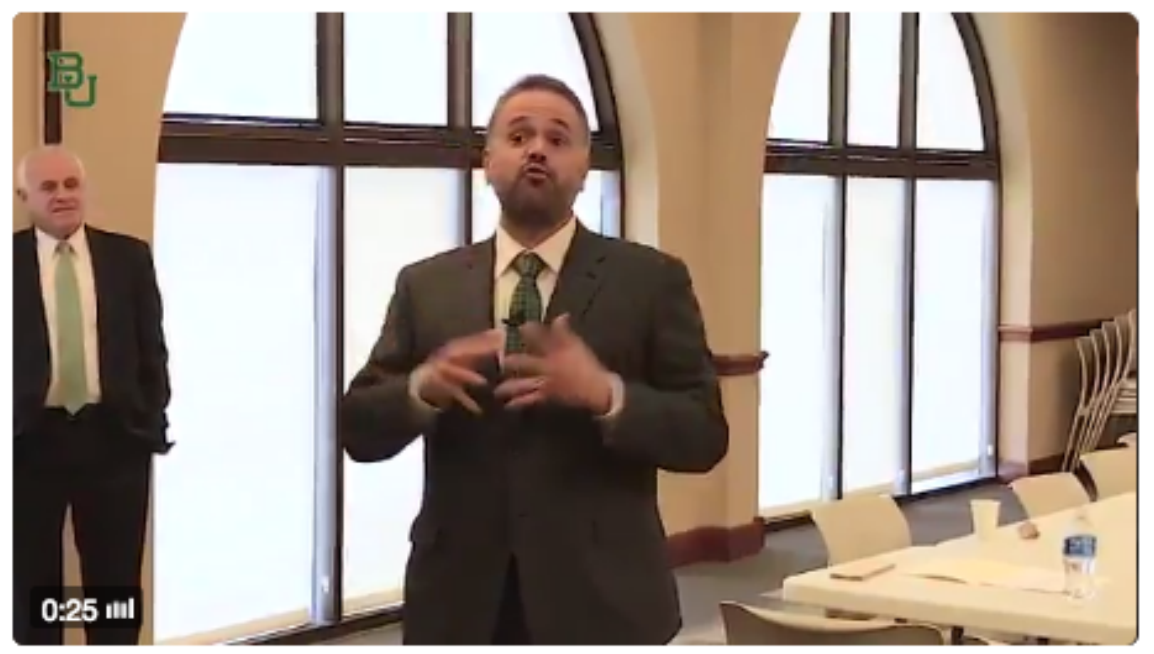

Coach Rhule greets the Baylor Family
4 4
ㄴㄱ 77
356 


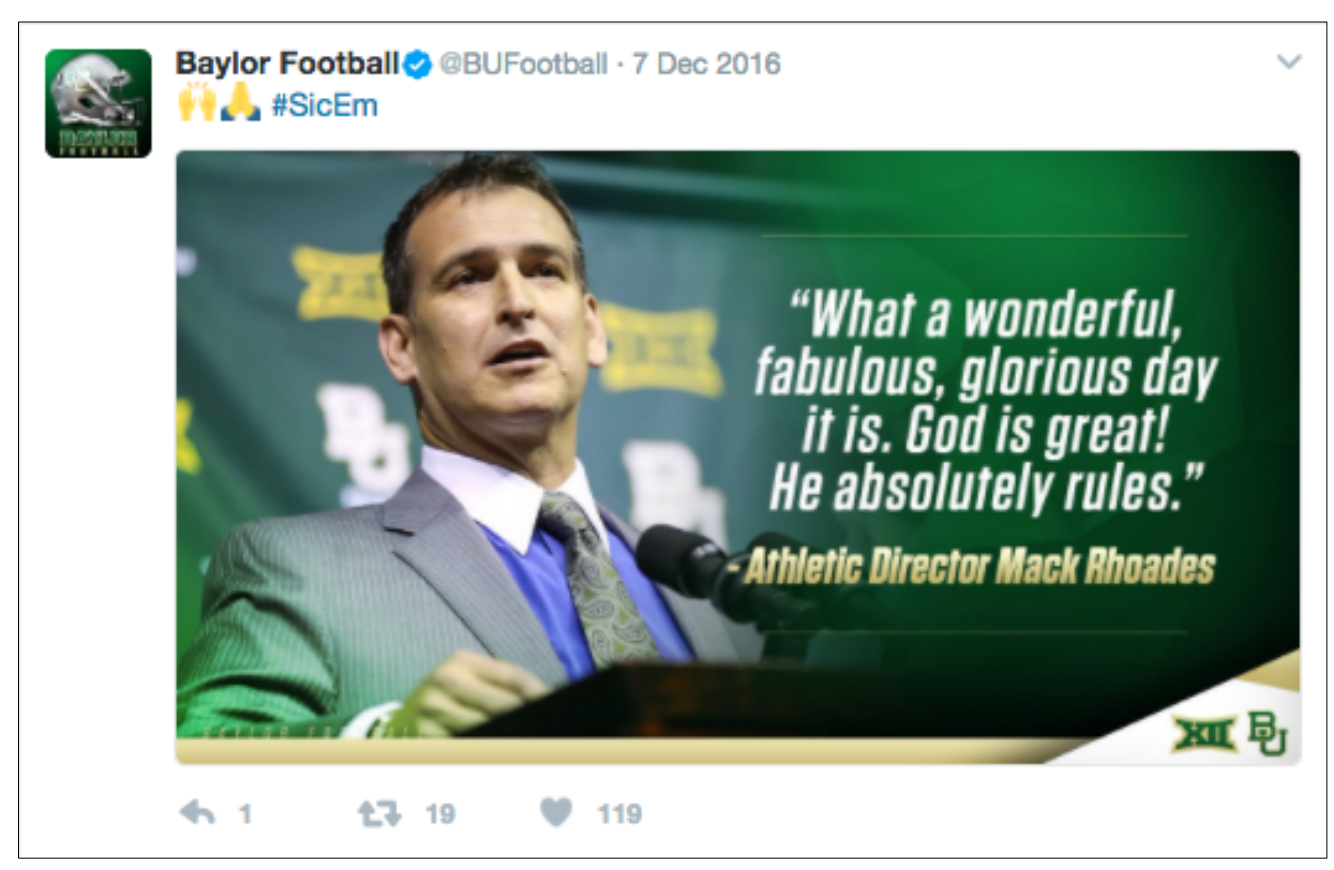

\section{Corrective action.}

Baylor Football @ @BUFootball · 3 Jun 2016

"I felt led to be here. A situation where I could not only coach football, but be part of the solution and help these kids." - Coach Grobe
4.1
ㄴ. 31
148

Baylor Football @ @UFootball · 25 Jul 2016

Thanks for the important message, Brenda.

Brenda Tracy @brendatracy24

Huge thanks to all of the @Baylor players who have tweeted me. I appreciate you \& remember the pledge you made to eachother! \#ItsOnUs

ค 


\section{@BaylorAthletics}

\section{Corrective action.}

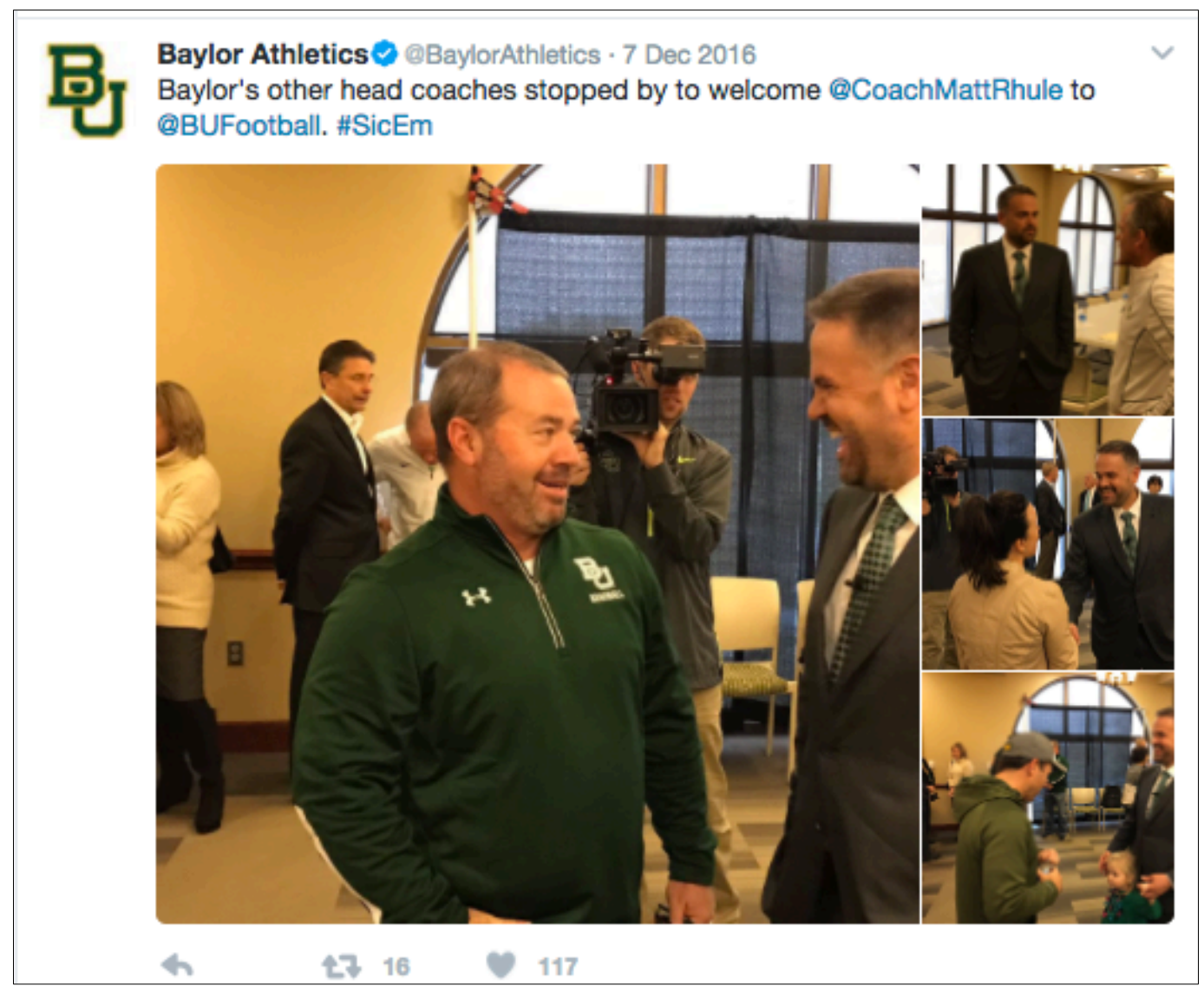

Diversion (Bruce and Tini, 2008).

Baylor Athletics $\$$ BaylorAthletics - Jan 27

"We are not who they say we are," Rhule said. "We are who we are. The guys who stay and move forward will be remembered for a long time."

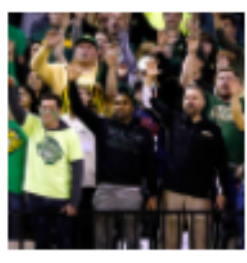

\section{CBS Sports CFB @}

How his upbringing turned outsider Matt Rhule into the change agent Baylor needs.

cbssports.com/college-footba...

ค 7 เา 47 ○ 178




\section{Appendix E}

Baylor fans' tweets organized by communication strategy and in the order they appear in the findings chapter.

\section{Scapegoat/Shift the Blame}

\section{Board of Regents.}

Jeff Summers @pressmyhardsix - 26 May 2016

Qkendalbriles please let your dad know that many of us in the Baylor family do not support the BOR decision. Thank you both for contributing

4 $27 \quad 01$

Brad Liles biffl - 30 May 2016

Gbu_ad1 Thanks for all youve done for BU. Class act all the way to the end.

You deserved better but rest assured Baylor Nation appreciates u

4 $27 \quad 04$

Mel Otxbarbydoll + 15 Jun 2016

Every single BaYlor BOR member should be investigated !! Release the report or get rid of them @BaylorAlumAssoc \&BUFootball @BaylorAthletics

h 27

dan: March Sadness eTXWayne-15 Jun 2016

Just provided the Baylor BoR a piece of my mind, I wonder if they are smart enough to use mail rules or just delete email manually? \#deaf

\& 27

Nick Morgan BaylorNick + 13 Jul 2016

Until there is a change in the @Baylor Board of Regents, it may not matter, sadly

Richard Justice $\theta$ irichardjustice

Mack Rhoades is a home run for @BaylorAthletics in every way. Great character. Always always tries to do the right thing.

\& 27 
@TXJoyce Would be perfectly OK with the entire BOR and every VP and higher position turning over. Baylor embarrasses me. Needs to stop. LIKE

1

11:52 AM - 5 Oct 2016

4 1 เ7 1

R. Reply to @jonschr @TXJoyce

BU2017Mom TXJoyce $\cdot 5$ Oct 2016

kas ejonschr That would be nice but who knows.

h 17

Ken Starr.

4. In reply to Baylor University

Keith Sena @keithsena + 7 Feb 2016

isBaylor

How Ken Starr is handling matters right now

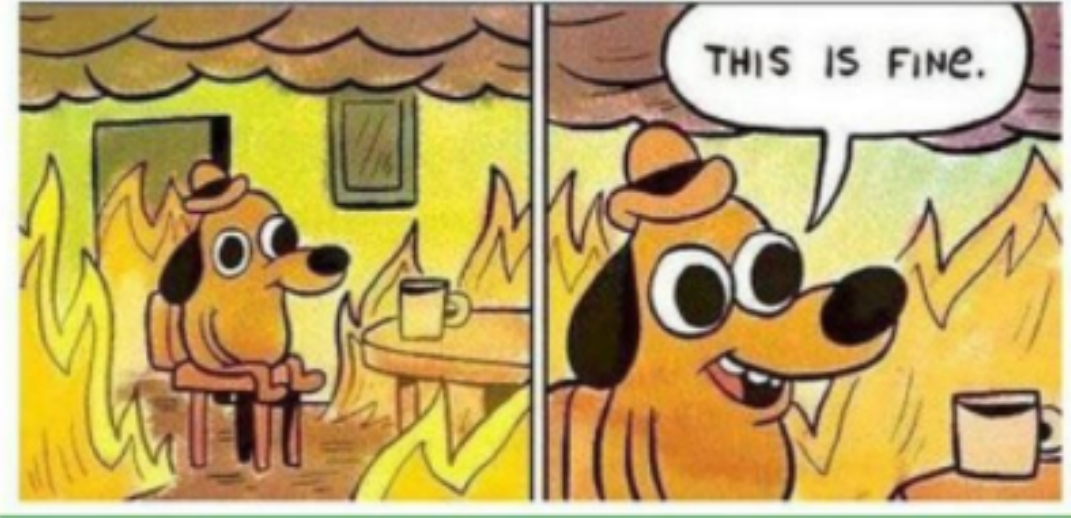

4 271 
C H R I S B Y R D @LittleByrdEee - 26 May 2016

It's egregious that 4 YABOYKENNYSTARR still is affiliated with Baylor. Ken

Starr should be held responsible and completely dismissed.

४ 1

七7

4. In reply to Shehan Jeyarajah

Dakota Day @dakotajday - 30 May 2016

(6ShehanJeyarajah I personally think that Ken star should step down as chancellor. Thats coming from a Baylor fan

ᄂ 2 เ7 9

Art Briles.

Baylor Bears

(1)

BBaylorGonnaBU

@Bear_Force they were left no choice. Briles knew and did nothing, he needs to be fired. That's what the independent report says.

LIKE

1

4:47 PM - 26 May 2016

4 1 เา 1

Drakers eDrakeHowe - Feb 3

Baylor fan yes! Fan of the way art briles and company handle these cases?

Nol Out with the old and in with the new! Baylor is making changes!

\& 271

Bears.Beets.Baylor efan_baylor · Feb 3

Thankful for truth and closure. I'm abhorred in what Briles and company

allowed in their complacency. Good riddance.

4 $27 \quad 02$ 
Clint Followell @FantasyPastor - Feb 3

As a Baylor alum it's disgusting to read these reports, but glad it is coming out and hope the program/Art Briles will be held accountable

Clint Followell @FantasyPastor

Art Briles is a monster "The football program was a black hole into which reports of misconduct ...disappeared," goo.gl/qB5apG

h 27

\section{Waco Police Department.}

Eric Jackson ๑ecjackson77 + 18 May 2016

It seems that the Waco police, along with Baylor, should be in hot water over all of this too.

Outside The Lines $\theta$ GOTLonESPN

Breaking: Police records obtained by OTL detail several more violence allegations against Baylor football players: es.pn/1THOBxt

h t7

\section{Public Relations Firm(s).}

4 In reply to Craig Smoak

Jason Fuller @GoBearsGo95 - 7 Feb 2016

(4) CraigSmoak @Baylor whatever PR firm is guiding BU needs to be fired.

h 17 . 1

Diversion (Brown and Billings, 2013)

\section{Specific Diversion.}

4 In reply to Paula Lavigne

Brad B. AAFBaylorBear - 31 Jan 2016

D. Bpinepaula In addition, Baylor has acknowledged these incidents and have tried to address them, while other universities (FSU) ignore them.

\& 27 
Brooke Bentley @BBentleyy - 6 Jun 2016

Thanks Stanford kid for switching up the headlines from Baylor for a bit.

4 $27 \quad 01$

Thee Bears etheebears - 15 Jun 2016

Sex offenses on U.S. college campuses - The Washington Post

Tcu \#1 in the state for rape of P5 universities

\begin{tabular}{|l} 
Sex offenses on U.S. college campuses \\
This table shows the number of alleged forcible sex \\
offenses on campus reported to security authorities at \\
colleges and universities or to law enforcement, as wel... \\
washingtonpost.com
\end{tabular}

Thee Bears otheebears - 15 Jun 2016

The point is, it's a problem everywhere. It's sad and pathetic how some fans react so they can hope to win more games.

Wash Post don't lie

4 3 ㄴ․ 2 \% 


\section{Broad Diversion.}

MargeBarry Olife_of_marge + 26 May 2016

Sexual assault does not discriminate. Its not just a Baylor problem, it's not just an athlete problem.

4 27,1

Bill Conant @twoscoopsofpig · 8 Nov 2016

Who says you can only report to one authority? Go elsewhere if you aren't

being heard. WPD, the Sheriff, Constables, State Troopers...

Drake @GannonDrake

Gtwoscoopsofpig ramsower heads the BPD- they were accused of not reporting. Thats ultimately his fault

4 2 เา

Drake

GGannonDrake

@twoscoopsofpig so do you think title ix is working out? Baylor aside, many, many campuses are having issues with this

1:51 PM - 8 Nov 2016

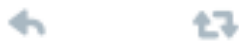




\section{Partial Diversion.}

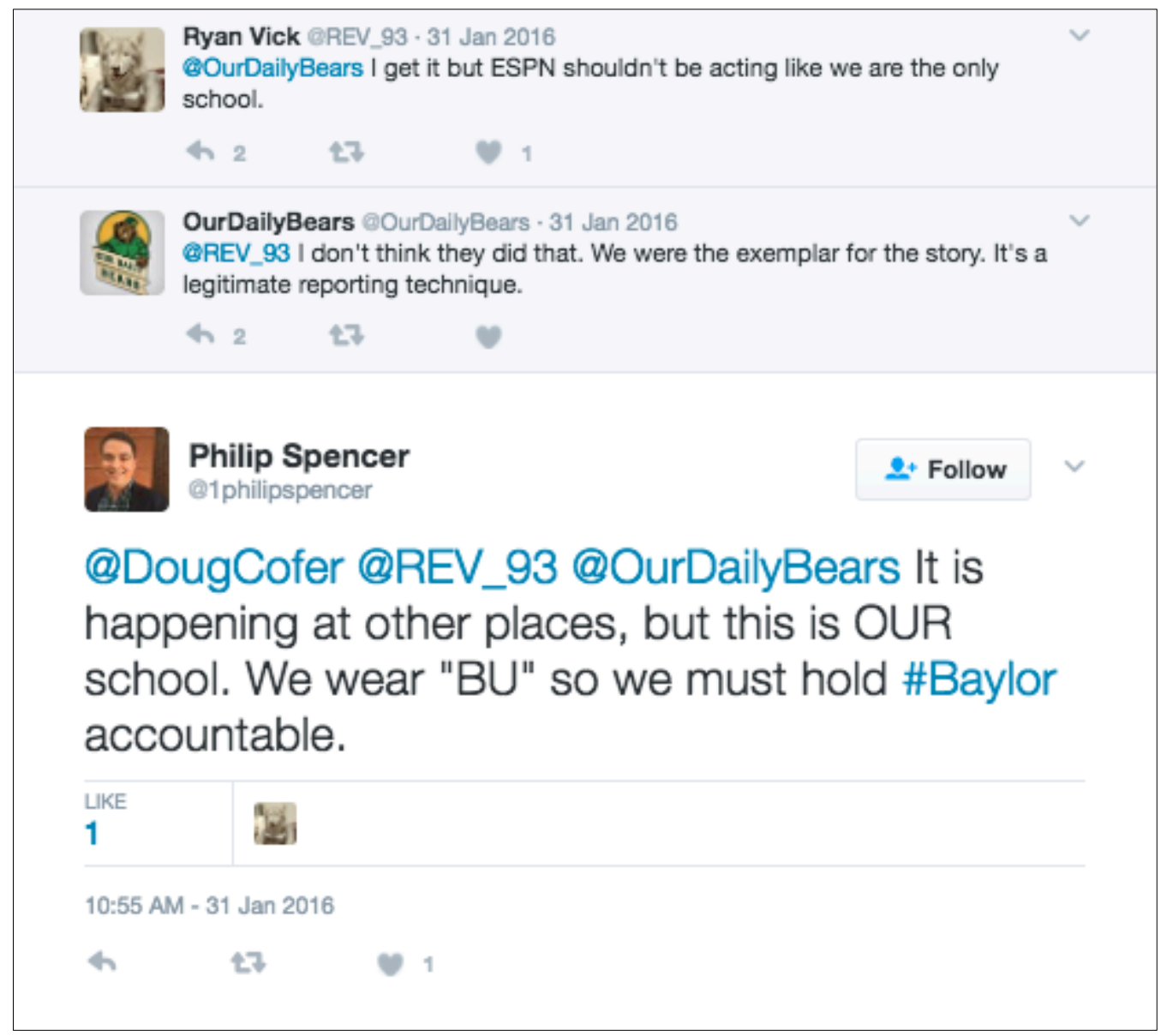




\section{Diversion to Previous Baylor Scandals.}

\section{Steve Thomas @sctvi - 26 May 2016}

Have to say, though, l'd think Baylor would have been a bit more prudent in managing the athletic department after the scandal in 2003.

h 27

Ryan Patrick @ryanpatrick177 - 1 Jun 2016

I remember dark days at Baylor in '03 when a basketball player killed a

teammate. That was horrible but this feels different - so systemic.

h 47

parker tadlock eTarkerPadlock - 13 Jul 2016

Anybody else find it EXTREMELY ironic that Baylor gave Bill Cosby an

honorary degree?

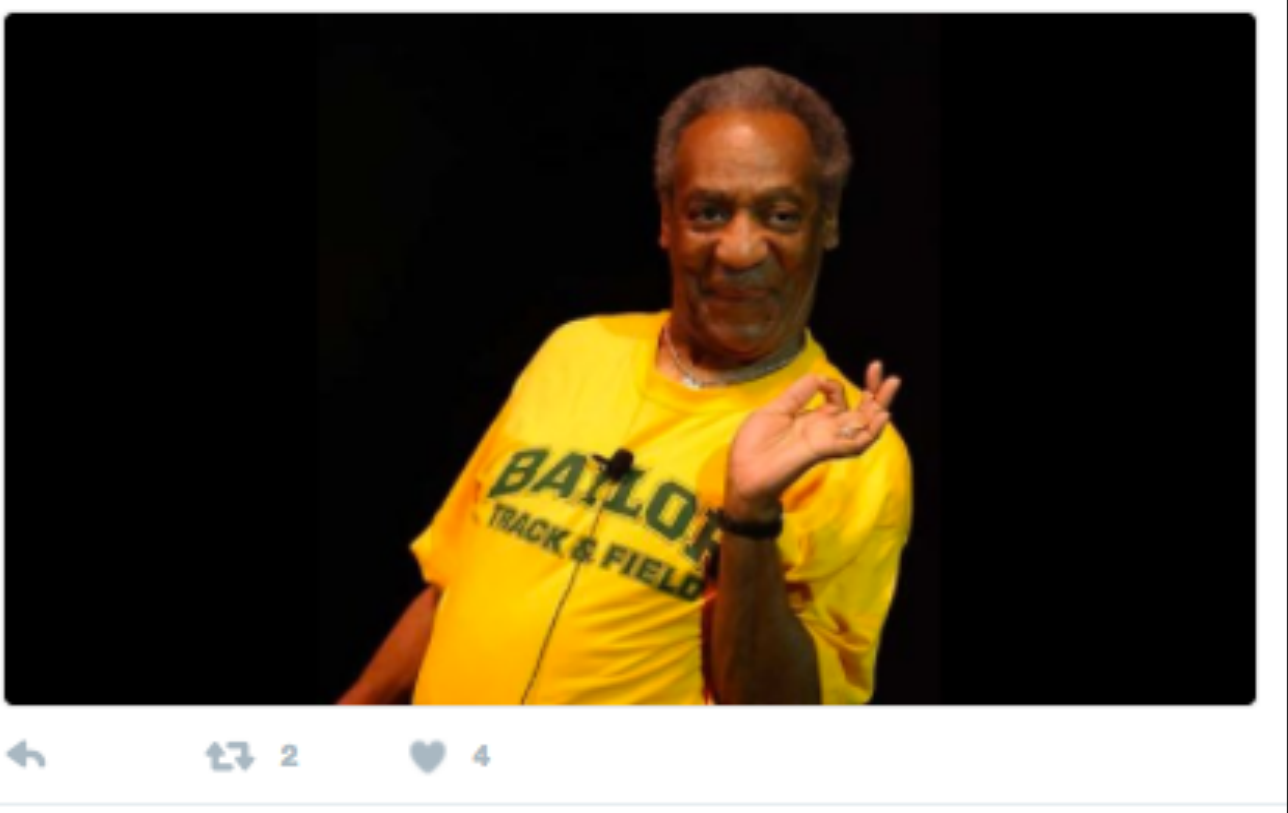




\section{Attack the Accuser}

\section{Outside the Lines and ESPN.}

ESPN Big 120 ESPN_Big12 + 18 May 2016

OTL: More police cases for Baylor football

OTL: More police cases for Baylor football

WACO, Texas -- As Baylor University's board of regents reviews a law firm's findings about the school's response to sexual violence allegations -- many involving its foot...

espn.com
4 2
ㄴㄱ 23
(1) 23

Football Bob

(eftblbob5

@ESPN_Big12 Waco police released a statement calling your piece sensationalism.

RETWEETS LIKES

2

2:42 PM - 18 May 2016

41

เา 2

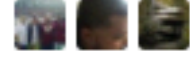

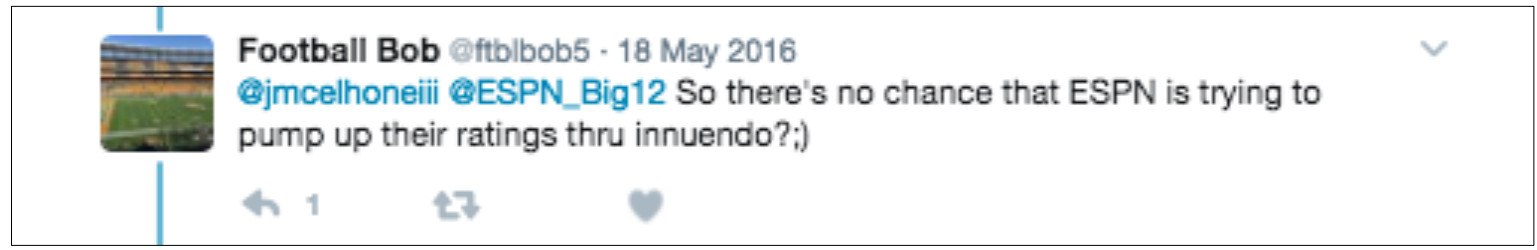

Tristan Maynard OTristanLMaynard - 19 Oct 2016

Being a Cowboys fan and a Baylor student, I have become real fed up with ESPN's negative media designed for attention and ratings.

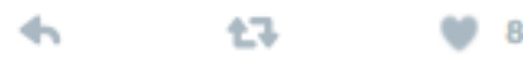


Thee Bears etheebears - 15 Jun 2016

Anyone noticed that Fox Sports isn't quite as outraged at \#BAYLOR as espn is?

Any thoughts as to why? Doesn't ESPN own the LHN? :). Mmmk
\& 7
273
19

Jon Schroeder @jonschr - 5 Oct 2016

Oh, come on. It was malpractice. They were right, in general, but missed the larger story. This was not about football.

\section{Greg Tepper ㅈepper}

Outside the Lines' coverage of the Baylor scandal has been a journalism masterclass. twitter.com/BobLeyESPN/sta...

h $27 \quad 01$

\section{Patty Crawford.}

\section{Jon Schroeder Ojonschr - 5 Oct 2016}

BTW, you realize that "protecting the brand" implies "kicking out any accused student immediately." That's the thing happening now.

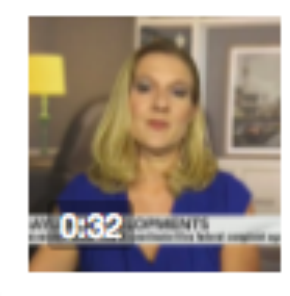

\section{Bob Ley $\odot$ BobLeyESPN}

Just how important is the Baylor brand to university officials? According to the school's former Title IX coordinator and ipinepaula, very.

Andrea Velasco Cayvelascoo - 5 Oct 2016

Patty Crawford cares so much about the students and their safety that she's tries to extort $2 \mathrm{mil}$ from Baylor and movie/book rights
4
272 


\section{Victims}

\begin{tabular}{|c|}
\hline $\begin{array}{l}\text { Bill Conant @twoscoopsofpig · } 8 \text { Nov } 2016 \\
\text { Who says you can only report to one authority? Go elsewhere if you aren't } \\
\text { being heard. WPD, the Sheriff, Constables, State Troopers... }\end{array}$ \\
\hline $\begin{array}{l}\text { Drake @GannonDrake } \\
\text { Replying to @twoscoopsofpig } \\
\text { ramsower heads the BPD- they were accused of not reporting. Thats } \\
\text { ultimately his fault }\end{array}$ \\
\hline h 2 \\
\hline
\end{tabular}

Taj Minajj O_UrSoREPLACED - Jan 27

There's such a gray area between what's actually rape and what's not. Most of them Baylor cases are girls regretting their actions.

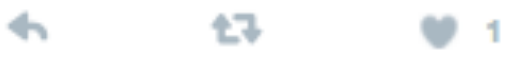




\section{Victimage}

David Ubben @davidubben - 13 Jul 2016

Good piece on uncertain times and an exit that's surprising in its destination and unsurprising in its occurrence

Ben Frederickson $\theta$ Ben_Fred

New at @stitoday: Mack Rhoades abandons \#Mizzou, makes Tigers punch line again stitoday.com/sports/columns...

$\begin{array}{lllll}4 & 1 & \text { t7 } & 1 & 5\end{array}$

\section{BU-Grizz}

eBuGrizz

@davidubben @Ben_Fred @stltoday Baylor not a bad place folks, great facilities, well funded...but victim of its own naivete.

LIKE

1

3:49 PM - 13 Jul 2016

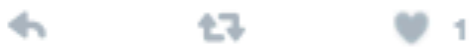

Lisa Marie

CLisaMarie

¿+ Follow

@brandyisme the story wouldn't have been this big had the $\mathrm{PH}$ report been kept internal \& Briles not fired. If Baylor had just made public 
Paula Lavigne @ Opinepaula - 31 Jan 2016

The law required action, but Baylor's response to women alleging rape by FB

players was more silence than support

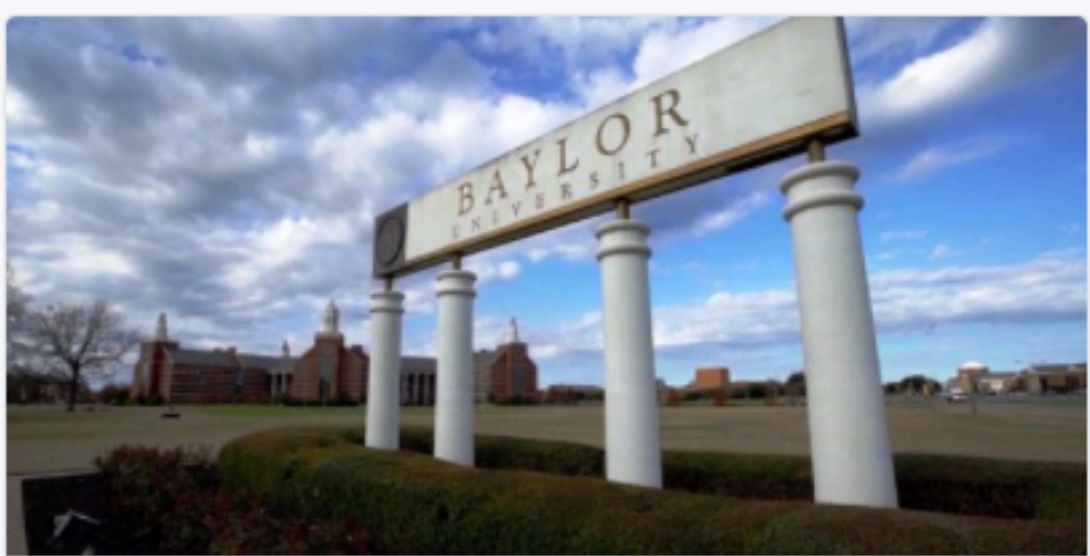

OTL: Women say Baylor ignored sexual assaults

An Outside the Lines investigation found several examples at Baylor in which school officials either failed to investigate, or adequately investigate...

espn.com

ค 42 เ7 668 ○ 348

Brad B.

BAFBaylorBear

@pinepaula Sounds like a hit piece to me. Baylor has not been silent. The suspects have all been expelled.

3:51 PM - 31 Jan 2016

4 27

$\mathcal{C}$

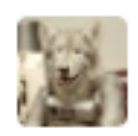

Ryan Vick @REV_93 - 31 Jan 2016

Replying to 8 OurDailyBears

@OurDailyBears I get it but ESPN shouldn't be acting like we are the only school.

H $27+91$ 
Drake @GannonDrake - 26 May 2016

People are absolute morons. Im so sick of media bombarding baylor as if baylor is the lone suspect...

Baylor Bearmada @BaylorBearmada

Good grief... twitter.com/ap_top25/statu...

4 47

\section{Differentiation}

\section{F Success Motivation @baylor_logan - 31 Jan 2016}

@UT_HookEm @Baylor this is an insane allegation. what ever happend to

innocent until proven guilty? And player never played a snap

H 1 나

Stephen Koehn Gkoehn_stephen + 6 Jun 2016

Replying to @inotthefakeSTU @WWMcClyde

false. should not be punished for ALLEGATIONS. Show me where multiple convictions were made. Then talk justice.

h 2 t?

SicEmSports 0 SicEmSports - Jan 27

Passing along

Dallas Morning News $\theta$ Bdallasnews

\#Breaking New Baylor lawsuit cites 52 rapes by football players in 4 years | @smervosh dallasnews.com/news/baylor/20...

4 4 는

Troy Cooper

(BCooper1440 BS. Possibly assault allegations but not rape!

2:23 PM - 27 Jan 2017 from Denton, TX

4 1 나 


\section{Bolstering/Reminder}

17. Success Motivation

(Bbaylor_logan

@RedRdr@keffjennedy @OTLonESPN lol you're judging an entire school of one incidence. Everyone is blowing up this story because our success

7:49 AM - 31 Jan 2016

h 47

Stephen Koehn Gkoehn_stephen · 6 Jun 2016

Replying to iWWMcClyde

blame who you want. End of the day: 1 conviction in 8 years.... Back to back Big12 champs... Can't take rings away

h 2

47

Gabe DeArmond OGabeDeArmond · 13 Jul 2016

No. Not in my opinion. But obviously Mack Rhoades believed that.

Chris Gbballkansas

\&GabeDeArmond MU a bigger mess than Baylor?

ค 7 เ 2 ○ 5

Jeff Edwards

Gbufree99

\section{Follow}

@GabeDeArmond compare all sports and facilities Baylor has to look more attractive. Football was a top 10 team and could still be.

2:51 PM - 13 Jul 2016 


\section{Ingratiation}

\section{Emily Alsup @actress 329 - 26 May 2016}

No matter what, I'll always be proud to be a Baylor Bear $\%$

h $477_{1} \quad 0_{6}$

Mama Abbs CVirtuouslySweet - 15 Jun 2016

Come " $\mathrm{t}$ come a Baylor \& I'll always be...

\& 271

Chris Fuentes

Qfuentbu1

2. Follow

@Tap219 Baylor Nation is behind our Bears! \#SicEm \#WeAreMore

LIKES

5

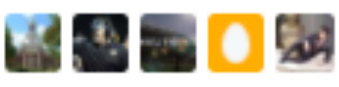

4:50 PM - 1 Jun 2016

4 